WILKER GLÉRIA DE OLIVEIRA

Estudo anatômico do cerebelo do macaco Cebus apella 
WILKER GLÉRIA DE OLIVEIRA

\title{
Estudo anatômico do cerebelo do macaco Cebus apella
}

\begin{abstract}
Dissertação apresentada ao programa de Pós-Graduação em Anatomia dos animais domésticos e silvestres da Faculdade de Medicina Veterinária e Zootecnia da Universidade de São Paulo para obtenção do título de mestre em Ciências
\end{abstract}

\section{Departamento:}

Cirurgia

Área de concentração:

Anatomia dos Animais Domésticos e Silvestres

Orientadora:

Prof ${ }^{a}$. Dr ${ }^{\mathrm{a}}$ Irvênia Luiza de Santis Prada

São Paulo 
Autorizo a reprodução parcial ou total desta obra, para fins acadêmicos, desde que citada a fonte.

DADOS INTERNACIONAIS DE CATALOGAÇÃO-NA-PUBLICAÇÃO

(Biblioteca da Faculdade de Medicina Veterinária e Zootecnia da Universidade de São Paulo)

T.1594 Oliveira, Wilker Gléria de

FMVZ Estudo anatômico do cerebelo do macaco Cebus apella / Wilker Gléria de Oliveira. - São Paulo : W. G. Oliveira, 2005.

$61 \mathrm{f}$ : : il.

Dissertação (mestrado) - Universidade de São Paulo. Faculdade de Medicina Veterinária e Zootecnia. Departamento de Cirurgia, 2005.

Programa de Pós-graduação: Cirurgia.

Área de concentração: Anatomia dos Animais Domésticos e Silvestres.

Orientador: Profa. Dra. Irvênia Luiza de Santis Prada.

1. Macacos. 2. Cerebelo. 3. Anatomia. 4. Cebus apella. I. Título. 


\section{UNIVERSIDADE DE SÃO PAULO \\ Faculdade de Medicina Veterinária e Zootecnia \\ Cidade Universitária "Armando de Salles Oliveira" \\ Comissão Bioética \\ CERTIFICADO}

Certificamos que o Projeto intitulado "Estudo anatômico do cercbelo do macaco Cebus apella", protocolo n $\mathrm{n}^{\circ} 340 / 2003$, utilizando 20 macacos, sob a responsabilidade da Profa $\mathrm{Dr}^{\mathrm{a}}$ Irvênia Luiza de Santis Prada, está de acordo com os princípios éticos de experimentação animal da Comissão de Bioética da Faculdade de Medicina Veterinária e Zootecnia da Universidade de São Paulo e foi aprovado "ad referendun".

(We certify that the Research "Anatomical study of the Cerebelium of the Cebus apella monkey" protocol number 340/2003, utilizing 20 monkeys, under the responsibility of Prof. Dr. Irvênia Luiza de Santis Prada, agree with Ethical Principles in Animal Research adopted by Bioethic Commission of the Faculty of Veterinary Medicine and Zootechny of University of São Paulo and was approved "ad referendun").

São Paulo, 30 de julho de 2003

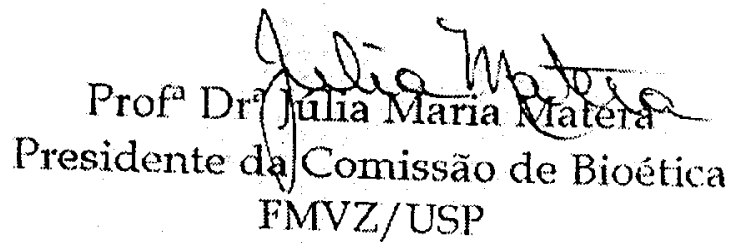




\section{FOLHA DE AVALIAÇÃO}

Nome: OLIVEIRA, Wilker Gléria de

Título: Estudo anatômico do cerebelo do macaco Cebus apella

Dissertação apresentada ao programa de Pósgraduação em Anatomia dos animais domésticos e silvestres da Faculdade de Medicina Veterinária e Zootecnia da Universidade de São Paulo para obtenção do título de mestre em Ciências

DATA

\section{Banca Examinadora}

Prof. Dr.

Instituição:

Assinatura: Julgamento:

Prof. Dr. Instituição:

Assinatura: Julgamento:

Prof. Dr. Instituição:

Assinatura: Julgamento: 


\section{Dedicatória}

A Deus, que sempre sabe da necessidade de cada filho, dando-lhe a força necessária para vencer suas provas.

Aos meus pais, José Dorival de Oliveira e Aparecida Gléria de Oliveira, que sempre estiveram ao meu lado, orgulhosos dos caminhos trilhados por este filho.

Aos meus irmãos, Weber Gléria de Oliveira e José Dorival Gléria de Oliveira, amigos de todas as horas e, nos quais, espero ter inspirado garra e determinação para seguir sempre em frente, superando todos os obstáculos, por mais difíceis que possam parecer. 


\section{Agradecimento especial}

À minha filha, Lara Loureiro Gléria, o meu ponto de referência em todas as decisões de minha vida. Você mudou minha vida completamente, sou muito mais forte agora, te amo.

À Professora Doutora Irvênia Luiza de Santis Prada, por ter me orientado não apenas no mestrado, mas para toda a vida. Obrigado por ter sido tão paciente comigo. Sua serenidade e disposição encantam a todos, são virtudes que exercito todos os dias e que proporcionam um grande enriquecimento profissional e espiritual.

Ao Professor Doutor Zenon Silva, meu mestre e amigo desde a graduação, sempre disposto a ajudar profissional e pessoalmente. Muito obrigado pelos conselhos e pela confiança depositada em mim. Seu comportamento constante dentro e fora da sala de aula evidenciam a firmeza do seu caráter.

À FAPESP (Fundação de Amparo a Pesquisa do Estado de São Paulo), por ter financiado este projeto de pesquisa. 


\section{Agradecimentos}

À Professora Doutora Maria Angélica Miglino, pela oportunidade concedida e compreensão nos momentos difíceis.

Aos técnicos da pós-graduação em Anatomia dos Animais Domésticos e Silvestres, da Faculdade de Medicina Veterinária e Zootecnia da Universidade de São Paulo: Edinaldo Ribas Faria (Índio), Diogo Nader Palermo, João do Carmo Freitas, Raimundo Leal de Souza e Ronaldo Agostinho da Silva, obrigado pelo auxílio nas atividades no decorrer do curso.

Aos funcionários da pós-graduação em Anatomia dos Animais Domésticos e Silvestres: Gracieta Aparecida Rodrigues Nogueira, Jaqueline Martins de Santana, Maicon Barbosa da Silva e Patrícia Aparecida R. da Paixão, obrigado pela atenção em todos os momentos, mesmo quando estavam muito atarefados.

Aos amigos do Departamento de Anatomia Humana da Universidade Federal de Uberlândia-MG: Anivanda Almeida Pereira, Lázaro Antônio dos Santos, Silvio Lemes de Carvalho, Vandecir Teixeira Magalhães, Gilmar da Cunha Sousa. 
Às minhas "irmãs" (em ordem alfabética): Adriana Rodrigues Ribeiro, Daniela Cristina de Oliveira Silva, Jupyraciara de Carvalho Barros, Karina do Valle Marques e Roseâmely Angélica de Carvalho Barros.

A todos os amigos da pós-graduação, com os quais passei momentos inesquecíveis, dentro e fora da Universidade. Neste caso não citarei nomes para não incorrer no risco de esquecer de alguém. Todos foram muito especiais de alguma maneira. 


\section{RESUMO}

OLIVEIRA, W.G de Estudo anatômico do cerebelo do macaco Cebus apella. [Anatomical study of the cerebellum of the Cebus apella monkey]. 2005. f. Dissertação (mestrado em Ciências) - Faculdade de Medicina Veterinária e Zootecnia, Universidade de São Paulo, São Paulo, 2005.

O gênero Cebus, representado por quatro espécies e várias subspécies, encontra-se geograficamente distribuído desde a América Central até o sul da América do Sul. Entretanto, sua anatomia é ainda muito pouco conhecida. É de fácil adaptação, podendo sobreviver em pequenas matas e restingas, mas a contínua destruição de seu habitat vem ameaçando, de forma progressiva, sua sobrevivência, o que vem ressaltar a importância de estudos dessa natureza. Considerando-se ainda as importantes funções do cerebelo, no controle e manutenção do equilíbrio corporal e do tono muscular, bem como no estabelecimento da postura e da harmonia e coordenação de movimentos, o presente trabalho tem a proposta de analisar, no $C$. apella, macro e mesoscopicamente, a disposição das estruturas de seu cerebelo. Com isso, tem-se por objetivo o melhor conhecimento do cerebelo do C. apella, o que nos permitirá tecer ilações a respeito de suas potencialidades funcionais, em comparação a outros primatas não-humanos, a mamíferos domésticos e ao homem. Foram utilizados 20 animais, 16 para analise macroscópica e 4 para mesoscopia, fixados e conservados em formol $10 \%$, pertencentes ao acervo de pesquisa do Prof. Dr. Zenon Silva, na Universidade Federal de Uberlândia, MG. Após conveniente preparo de cada peça, macroscopicamente foram observados os hemisférios cerebelares, que se mostram pouco desenvolvidos em relação ao verme. No corpo do cerebelo, foram identificadas três porções, os lobos anterior, posterior e flóculonodular, assim constituídos, 
respectivamente: língula, lóbulo central, bastante desenvolvido, assim como suas asas, cúlmen e lóbulo quadrangular anterior; declive, lóbulo, quadrangular posterior, folha do verme, lóbulos semilunares, bem caracterizados na região equatorial dos hemisférios, sendo um superior e um inferior, túber, pirâmide, tonsilas bem desenvolvidas, e lóbulo biventre também bem demarcado. São bem evidentes as fissuras primária (entre os lobos anterior e posterior), horizontal (entre os lóbulos semilunares superior e inferior), secundária (póspiramidal) e a póstero-lateral (separando o nódulo e a úvula e os hemisférios do lobo floculonodular), intraculminal e pós-clival. Outras fissuras menos evidentes são a précentral, pré-culminal, pré-piramidal e intra-biventre. Os cortes para análise dos aspectos morfológicos internos, foram efetuados segundo os planos sagital mediano e horizontal, com espessura de 2 a $3 \mathrm{~mm}$, sendo corados pelas soluções de Mulligan. As estruturas evidenciadas são descritas com detalhes comparando-se os dados obtidos com os da literatura consultada. Os termos anatômicos foram referidos segundo a Terminologia Anatômica (Internacional), 1ª Edição brasileira - 2001, Ed. Manole Ltda.

Palavras-chave: Macacos. Cerebelo. Anatomia. Cebus apella. 


\begin{abstract}
OLIVEIRA, W.G de Estudo anatômico do cerebelo do macaco Cebus apella. [Anatomical study of the cerebellum of the Cebus apella monkey]. 2005. 61f. Dissertação (Mestrado em Ciências) - Faculdade de Medicina Veterinária e Zootecnia, Universidade de São Paulo, São Paulo, 2005.
\end{abstract}

The gender Cebus, represented by four species and several subspecies, it's found geographically distributed since Central America up to the south of South America however, its anatomy is still little well-known. Its from easy adaptation and can survive in small forests and restingas, but the continuous destruction of its habitat has been threatening, in a progressive way, its survival, what point the importance of these kinds of study. Considering still the important cerebellum's function at the control and maintenance of body equilibrium and muscle tonus, as well as the estabilishement of posture, harmony and movements coordenating, the present work proposes to analyze, on C. apella, macro and mesoscopically, the disposition of structures at its cerebellum. This way the objective is to know better $C$. apella's cerebellum, what will allow us to weave related to its functional potentialities comparing to other no-human primates, domestic mammals and human. Its was used 20 animals, 16 to macroscopic analysis and 4 mesoscopic fixed and kept in of formaldehyde $10 \%$, belonging to the research of Professor Dr. Zenon Silva, at Universidade Federal de Uberlândia, MG. After convenient prepare of each part, it was macroscopically observed the cerebellum hemispheres that seems little developed in relation to the worm. At 
cerebellum's body, it was identified three portions, the previous lobe, posterior and floculonodular, like this respectively constituted: língula, central lobule plenty developed, as well as its wings, cúlmen and previous quadrangular lobule, declive, posterior quadrangular lobule, worm's leaf, semilunar lobules well characterized at equatorial region of the hemispheres, being one above and one below, túber, pyramid, well developed tonsil and biventer lobule also well demarcated. Its very obvious the primary fissure (between the previous and posterior lobe), horizontal (between the superior and inferior lóbules semilunar) secundary (post-pyramidal) and the posterolateral (separating the nodule and the uvula and the hemisphere of lobe floculonodular), intraculminal and post-clival. Other less obvious fissures are the pré-central, pré-culminal and intra-biventer. The cuts to morfological internal analysis were effected according to the average and horizontal sagittal plans, with tickness from 2 to $3 \mathrm{~mm}$, being colours by muligan's solutions. The obvious structures are described with details comparing the data obtained with the researched literature. The anatomic terms were refered according to the Anatomic Terminology (International), first Brazilian edition- 2001, Ed. Manole Ltda.

Key Words: Monkeys. Cerebelum. Anatomy. Cebus apella . 
SUMÁRIO

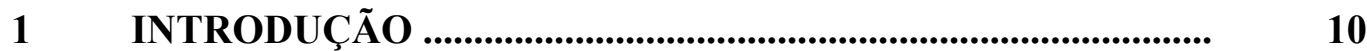

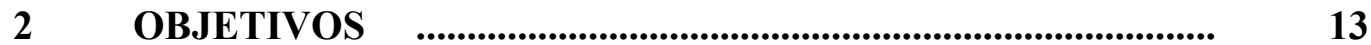

3 REVISÃO DE LITERATURA _.................................................... 14

$4 \quad$ MATERIAL E MÉTODO ............................................................ 37

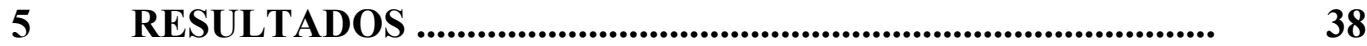

5.1 ASPECTOS MORFOLÓGICOS DA SUPERFÍCIE EXTERNA.... 38

5.1.1 Lobo Anterior............................................................................. 43

5.1.2 Lobo Posterior.................................................................... 45

5.1.3 Lobo Floculonodular.............................................................. 47

5.2 ASPECTOS MORFOLÓGICOS DE SUPERFÍCIE DE CORTES... 48

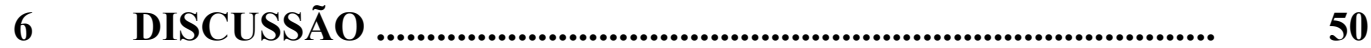

6.1 LOBO ANTERIOR ...................................................................... 52

6.2 LOBO POSTERIOR …................................................................. 54

6.3 LOBO FLOCULONODULAR ................................................... 56

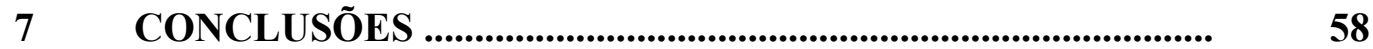

REFERÊNCIAS ........................................................................ 


\section{INTRODUÇÃO}

A Anatomia do macaco Cebus apella tem se revelado muito interessante, não apenas pela sua semelhança com a de outros primatas, inclusive o homem, como pelo fato de a ela estarem associadas características peculiares no campo da fisiologia e da etologia.

Por outro lado, temos observado que os primatas não humanos vêm sendo enfocados, cada vez mais, quando o objetivo é a compreensão de aspectos evolutivos das espécies, particularmente daqueles comuns ao homem e a outros animais.

Os primatas não-humanos têm-se constituído em importante grupo, dentre os animais submetidos a estudos diversos, o que se reveste de suma importância para o entendimento de sua própria evolução, somando-se ao fato de que o conhecimento pormenorizado de sua Anatomia pode representar fator importante para sua preservação e proteção (CARVALHO-BARROS, 2002).

O macaco Cebus apella é um primata que se caracteriza por apresentar tamanho médio, podendo chegar a 5 ou $6 \mathrm{~kg}$, pêlos pretos ou de cor castanha de várias matizes, sendo mais comum o castanho escuro. Os membros pélvicos são um pouco mais longos do que os torácicos, os dedos possuem tamanho médio e são moderadamente diferenciados. $\mathrm{O}$ terço distal da cauda é mais enrolado do que o restante, denotando razoável preensibilidade. 
A aparência da genitália externa pode gerar confusão, porque o clitóris é desenvolvido, à semelhança do pênis, e o escroto é séssil (sic) (NAPIER; NAPIER, 1967).

É uma espécie de fácil adaptação, podendo sobreviver em pequenas matas, restingas e outros ambientes, sendo que a destruição contínua do seu habitat vem ameaçando, de forma progressiva, a sobrevivência não somente do Cebus apella como de outras espécies, o que vem ressaltar a importância de estudo destes animais (SANTINI, 1983).

Orr (1978) cita a existência de onze gêneros de Cebídeos, os quais habitam desde o México até a Argentina.

Atualmente são consideradas quatro espécies do gênero Cebus: Cebus capucinus, na América Central e norte da Colômbia; Cebus nigrivittatus, no norte da América do Sul; Cebus albifrons, da Colômbia à Bolívia e o Cebus apella. No Brasil habitam várias subespécies de Cebus apella, tais como: Cebus apella apella, do norte da América do Sul até o baixo Amazonas; Cebus apella libidinosus, no nordeste, nos Estados do Maranhão, Piauí e Pernambuco, chegando ao longo do rio São Francisco até o oeste da Bahia e ao extremo noroeste de Minas Gerais; Cebus apella macrocephalus, na Amazônia; Cebus apella nigrivittatus, no sudeste, no Estado do Rio de Janeiro, leste de São Paulo, Paraná, Santa Catarina e Rio Grande do Sul; Cebus apella pallidus, na região de fronteira entre Brasil e Bolívia e noroeste do Mato Grosso; Cebus apella paraguayanus, no sul do Mato Grosso e extremo sudoeste de Goiás; Cebus apella robustus, no leste de Minas Gerais e no Espírito Santo; Cebus apella vallerosus, no oeste dos Estados de São Paulo, Paraná e Santa Catarina; Cebus apella versutus, na região centrooeste, no oeste de Minas Gerais e noroeste de São Paulo e Cebus apella xanthosternos, na região oriental e no leste da Bahia. (CABRERA, 1957, apud BROWN; COLILLAS, 1983) 
Para o desenvolvimento deste trabalho, tivemos interesse em estudar o Cebus apella, também por ter sido essa espécie já enfocada durante o período de nosso estágio nos laboratórios de Anatomia da Universidade Federal de Uberlândia, sob a orientação do Prof ${ }^{a}$. Dr. Zenon Silva, que permitiu a continuidade de acesso ao material constante do seu acervo de pesquisas.

A utilização do Cebus apella, em estudos, tem crescido muito nos últimos tempos, em razão do seu pequeno porte, fácil manuseio e relativa facilidade de se reproduzir em cativeiro. A estes fatores deve-se, ainda, acrescentar o fato de que apresenta grandes semelhanças com outras espécies de primatas, mormente no que diz respeito à sua Anatomia; além disso, é freqüente em nossa região e ainda não ameaçado de extinção.

Ressalte-se, ainda que, apesar de o Cebus apella caracterizar-se como espécie de farta ocorrência na América do Sul, a obtenção de espécimes para pesquisa constitui-se em objeto de profunda reflexão de natureza ética, pois estamos motivados a atender aos postulados dos novos paradigmas da Ecologia e a respeitar o direito desses animais, à sua própria vida. Portanto, nossa opção é a de não eutanasiar animais para a pesquisa.

O estudo do cerebelo desta espécie é importante e de grande interesse, devido ao fato de tal estrutura ser responsável pelo controle dos movimentos finos, podendo sua comparação com outras espécies de mamíferos trazer subsídios para a explicação de alguns comportamentos dos animais. 


\section{OBJETIVOS}

O objetivo deste trabalho foi o de conhecer a estrutura anatômica macroscópica interna e externa do cerebelo do macaco Cebus apella e, a médio e a longo prazos, dar seqüência ao estudo dessa espécie animal, visando o estabelecimento de seu padrão anatômico, culminando com a elaboração de um Atlas-texto, o qual fornecerá subsídios para futuras interpretações e melhor entendimento da evolução da própria espécie, além de auxiliar na sua preservação. 


\section{REVISÃO DE LITERATURA}

Zimmerl (BOSSI et al., 1909), tratadista que enfoca a Anatomia de Animais Domésticos, apresenta uma descrição clássica do cerebelo podendo-se, entretanto, destacar os aspectos que se seguem, em uma abordagem geral:

O lobo mediano divide-se em vários lóbulos mais ou menos distintos, os quais a partir de sua extremidade ventral são: língula, lóbulos centrais, montículo, cúlmen e declive. O lóbulo semilunar inferior é chamado de extrapeduncular, encontrando-se lateralmente ao pedúnculo cerebelar e constitui a parte pouco saliente deste hemisfério, sendo percorrido por um sulco transversal que o divide em duas partes; refere-se ainda a um lóbulo aliforme, situado lateralmente ao declive e ao cúlmen.

Este autor afirma ainda que, nos vertebrados inferiores, o cerebelo é pouco desenvolvido e vai aumentando progressivamente na escala zoológica; é formado por um só lobo nas serpentes, sendo que, somente nos crocodilos e nas aves acha-se composto por dois lobos laterais, os quais são sempre mais desenvolvidos nos mamíferos, até alcançar sua maior dimensão nos primatas e no homem.

A substância cinzenta constitui, além do córtex, pequenas massas centrais, os núcleos, mergulhados na substância branca. São eles: denteado, denteado acessório e do teto.

Os núcleos denteados são em número de dois, um direito e um esquerdo, conhecidos ainda como olivas cerebelares ou corpos romboidais. São situados medialmente no 
hemisfério correspondente e resultam constituídos de uma lâmina de substância cinzenta disposta em saco, irregularmente pregueada e aberta medialmente (hilo do núcleo denteado).

Os núcleos denteados acessórios são mal distintos nos animais; encontram-se medialmente ao núcleo denteado, sendo em número de dois, distintos em: núcleo denteado acessório externo ou embolo e núcleo denteado acessório interno ou globoso. O núcleo do tecto (núcleo fastigial) corresponde ao lobo mediano e ocupa os centros medulares, colocado junto ao plano mediano, vindo a encontrar-se, portanto, próximo ao do outro antímero.

Zimmerl et al. (1930) descrevem o cerebelo do eqüino, ocupando a parte posterior da cavidade craniana, que por isso recebe o nome de cavidade cerebelar. Os hemisférios cerebelares correspondem cranialmente aos hemisférios cerebrais, dos quais são separados pelo tentório do cerebelo. Ventralmente, o cerebelo encontra-se em relação com a face dorsal da ponte e do bulbo, do qual está separado por uma profunda incisura (incisura cerebelo-bulbar), destinada a receber a tela corióidea do quarto ventrículo.

O cerebelo é uma massa nervosa de cor cinzenta e forma globosa, ligeiramente alongada transversalmente. No eqüino, seu diâmetro ântero-posterior é de cerca de $55 \mathrm{~mm}$, o transversal de $65 \mathrm{~mm}$ e, o vertical, de $45 \mathrm{~mm}$. O seu peso absoluto, no cavalo é em média, de 70 gramas.

O cerebelo é formado por três lobos: um mediano e dois laterais, com superfície percorrida por sulcos, os quais aprofundam-se rumo ao núcleo central subdividindo-o em lóbulos, os quais por sua vez são subdivididos por outros sulcos mais superficiais, em pequenas lâminas. 
O lobo mediano ou verme tem a forma de uma proeminência que circunda sagitalmente o cerebelo em forma de anel incompleto ventralmente, cujas extremidades chegam a tocar-se. Por sua superfície ser regularmente subdividida em lâminas, foi comparado à disposição morfológica do bicho da seda, daí advindo-lhe o nome de verme. $\mathrm{O}$ lobo mediano divide-se em duas metades, que pelas suas posições são chamadas de verme dorsal ou nasal e verme ventral ou caudal. O primeiro apresenta-se mais largo e menos saliente que o segundo e encontra-se dividido mais regularmente em lâminas que se prolongam até os lobos laterais.

Os dois vermes apresentam-se divididos em lóbulos os quais, para a porção dorsal, a começar de sua extremidade livre são: língula, lóbulo central, cúlmen, folha do verme; para o verme caudal, também a partir de sua extremidade livre temos a úvula, pirâmide, tubérculo do verme.

A extremidade dos dois vermes, a língula e o nódulo unem-se totalmente a uma pequena lâmina nervosa, sendo a primeira o véu medular anterior e, a segunda, o véu medular posterior.

Os lobos laterais ou hemisférios cerebelares formam duas grossas proeminências arredondadas, situando-se lateralmente ao verme e unindo-se ventralmente à ponte pelos pedúnculos cerebelares médios.

A sua superfície é percorrida por um sulco profundo que a subdivide em lóbulos, nos quais contamos em número de cinco para cada hemisfério, sendo:

O lóbulo quadrangular, situado lateralmente ao montículo, com o qual sua lâmina continua-se; o lóbulo semilunar superior, situado caudalmente ao anterior; o lóbulo semilunar inferior ou extrapeduncular, que se encontra lateralmente aos pedúnculos cerebelares médios, constituindo a parte mais proeminente dos hemisférios cerebelares; o 
flóculo, que se encontra aplicado à face lateral dos hemisférios cerebelares, ventralmente ao anterior, do qual pode considerar-se como uma dependência; a tonsila, que está situada abaixo, entre o flóculo e a úvula.

Os pedúnculos cerebelares são três pares de cordões nervosos que unem o cerebelo às outras partes do rombencéfalo e ao mesencéfalo, que por suas posições podem ser distintos em caudal, médio e cranial.

Os pedúnculos cerebelares caudais ou posteriores (corpos restiformes) são dois grossos cordões que pertencem, como visto anteriormente, à medula oblonga, limitando lateral e caudalmente o quarto ventrículo e, cranialmente, alcançando a face ventral dos hemisférios cerebelares, nos quais penetram.

Os pedúnculos cerebelares médios são os mais volumosos, representando a continuação da ponte, da qual são separados por um plano, convencional, que passa dorsalmente à raiz do trigêmeo, dirigindo-se ao topo e alcançando a face ventral dos hemisférios laterais, nos quais penetram.

O pedúnculo cerebelar cranial pertenceria, pelo seu desenvolvimento, ao istmo do rombencéfalo, mas por suas relações é considerado como metencéfalo. São dois grossos cordões que limitam lateral e cranialmente o quarto ventrículo, convergindo adiante para situar-se na parte inferior da lâmina quadrigêmea, adentrando-se caudalmente na face ventral dos hemisférios.

Entre o pedúnculo cerebelar cranial encontra-se estirada uma lâmina de tecido nervoso conhecida como véu medular anterior. Entre os posteriores encontra-se, ao contrário, o véu medular posterior.

Bruni e Zimmerl (1947), autores de Tratado de Anatomia dos Animais Domésticos, 
citam que, ao corte sagital mediano, o cerebelo mostra a substância cinzenta formando, em toda sua superfície, um estrato contínuo de pouco mais de $1 \mathrm{~mm}$ de espessura, que reveste a massa de substância que constitui o corpo medular. Este último forma no centro do órgão o núcleo branco, que se prolonga no eixo dos lóbulos e das lamelas, dividindo-se e subdividindo-se para formar as lâminas medulares. Em secção vertical representa uma figura característica, que recebe pelos antigos anatomistas o nome de árvore da vida. Porém, a substância cinzenta também é encontrada no corpo medular, e forma em cada antímero, quatro núcleos.

O núcleo denteado é o mais lateral, e pertence ao verme. É composto por uma pequena lâmina de cor cinzenta escura, pregueada e disposta em forma de uma bolsa alongada no sentido sagital, com abertura ou hilo dirigido anteriormente, para o alto e medialmente. A sua superfície é revestida por uma cápsula branca (Véu); a cavidade é totalmente preenchida por substância branca, que no hilo se continua com aquela da cápsula.

Os núcleos emboliforme e globoso são mal distintos. O núcleo do tecto ou fastigial é o mais medial de todos, situado logo acima da incisura do tecto.

Hill (1962) relata que em Ateles, o cerebelo foi descrito por Bolk (1902b). Externamente o órgão apresenta uma semelhança com o cerebelo humano, sendo largo, relativamente liso, e dorsoventralmente achatado. Ele é completamente coberto dorsalmente pelos lobos posteriores dos hemisférios cerebrais. A árvore da vida está arranjada como em Cebus, destacando-se que a fissura primária é mais vertical que em Alouatta. Com o achatamento dorsoventral, os sulcos anterior, posterior e as partes 
correspondentes da árvore da vida estão dispostos mais horizontalmente que em Cebus, e, portanto, a divisão em folhas é mais minuciosa no espaço entre as fissuras principais.

O flóculo e paraflóculo estão inteiramente escondidos, exatamente como a expansão do lobo ansiforme. A borda caudal do cerebelo mostra proeminências pareadas formadas pelos lobos laterais separados pelo corte (paramediano) do estreito verme, o qual não se projeta tão caudalmente como os lobos laterais. Inferiormente a borda cranial do cerebelo forma uma concavidade uniforme percorrida por um sulco. O sulco é mais irregular que em Cebus e cebídeos inferiores, sendo parcial em alguns, completos em outros, podendo um sulco particular, ser parcial em um único lado e completo no outro.

O flóculo e o paraflóculo são merecedores de nota, sendo ambos claramente definidos. O flóculo é uma faixa sagital estreita composta de sete folhas arredondadas, contrastando com a larga massa arranjada em forma de pluma formada pelo paraflóculo projetando da folha. $\mathrm{O}$ verme projeta-se posteriormente, ligeiramente à frente dos lobos laterais.

No gênero Lagothrix, o cerebelo parece-se muito com o de Alouatta, sendo os lóbulos floculares especialmente similares, sendo o lóbulo petroso do paraflóculo muito evidente.

Wirth e O’Leary (1974), estudando o comportamento locomotor de mamíferos arbóreos com o cerebelo parcial ou completamente removido, compararam as taxas relativas de recuperações de lesões cerebelares experimentalmente induzidas, usando parâmetros de escaladas, corridas no solo e natação, em guaxinins (Procyon lotor) e 
macacos (Macaca mulata). Para estes autores as habilidades em caminhar, escalar e nadar, são geneticamente determinadas por serem programas universalmente requeridos na cinemática dos animais. O cerebelo é visto como o principal regente de cada um dos diversos programas locomotores listados acima, participando, em conjunção como os aferentes somático e vestibular, além das influências cerebrais.

Durante a escalada dos guaxinins e macacos decerebelados, os resultados foram equivalentes quando eles conseguiam agarrar a corda num ponto acima daquele do repouso, realizando movimentos fracionados, segurando a corda rapidamente ao passar de um ponto de apoio para outro. Os tremores apresentados pelos animais não dependiam da presença de resíduos dos núcleos centrais.

Em comparação com as observações de macacos decerebelados por outros autores, afirmam que os macacos e guaxinins totalmente cerebelectomizados de seus experimentos não ficaram profundamente incapacitados, nem eram tão incapacitados como os gatoscontrole decerebelados.

A retenção da habilidade de nadar dos guaxinins e macacos decerebelados é também importante por distinguir estes animais daqueles que apresentam perdas vestibulares. Dois macacos dentre os analisados, com lesão bilateral no nervo vestibular mostraram uma completa desorientação enquanto nadavam debaixo da água, porém o problema desapareceu durante a compensação.

Os estudos do desempenho da recuperação durante a escalada e caminhada no solo sugerem que os sistemas funcionais extensores são mais comprometidos pela cerebelectomia nos macacos e guaxinins do que os dos flexores, que são os principais na subida vertical e caminhadas para trás quando os animais encontram-se dependurados em um galho horizontal. Nenhuma das duas espécies foi capaz de correr efetivamente, por 
diversos meses, e alguns animais não puderam caminhar adequadamente durante seis meses.

Os efeitos diferenciais da cerebelectomia total, nos flexores e extensores dos membros foram avaliados segundo diferentes graus de dependência dos grupos musculares, do controle cerebelar. Os autores relatam ainda que parecia provável que o sistema corticoespinhal estivesse envolvido em recuperações mais rápidas dos sistemas flexores.

Das experiências de cerebelectomia descritas, pareceu sugestivo que guaxinins, mesmo com remoção total do cerebelo ou de um dos antímeros, acompanhada de isolamento do córtex cerebral motor contra-lateral, mantinham sua capacidade de escalar/subir. Porém, nenhum guaxinim hemidecerebelado, com remoção do córtex cerebral sensorial e motor contra-lateral, nem totalmente decerebelado com remoção do córtex cerebral sensorial bilateral poderia executar tal tarefa.

Os guaxinins com cerebelo intactos, privados de representação cortical motora ou sensorial bilateralmente, podiam reaprender a escalar utilizando os dois antímeros.

Um guaxinim que apresentava apenas uma ansoparamedianectomia bilateral mostrou inicialmente uma moderada dificuldade com o uso das patas traseiras na escalada. O rompimento da via vestibular em qualquer um dos antímeros, ocasionado pela remoção do flóculo e nódulo, como uma parte da cerebelectomia total, pode também ser acompanhado por uma disparidade entre escalar e o desempenho motor no solo.

Um macaco com secção bilateral no oitavo nervo, logo após a operação foi capaz de escalar, preferindo esta forma de locomoção. Em contraste, ele caminhou com grandes espaços entre as extremidades dos membros (base alargada), indicativo de dificuldade de equilíbrio. Este macaco foi capaz de caminhar melhor e correr com quatro semanas de pós- 
operatório, do que animais decerebelados observados durante seis semanas, e não apresentou tremores ou ataxia.

O hipertono extensor discutido no gato, causado pela remoção do lobo anterior, liberando os mecanismos de inibição paleocerebelar do sistema nervoso foi evidenciado no pós-operatório dos guaxinins, embora menos severo nos gatos-controle. Este quadro melhorou com o tempo, mas explicava a postura assumida pelos guaxinins decerebelados durante a escalada na corda.

A conclusão foi que, embora o cerebelo em animais arbóreos seja essencial para modular o controle efetivo do movimento, sua remoção não foi causa de uma perda permanente nas habilidades em escalar e nadar. A força, quantificada em macacos treinados para levantar pesos, foi também recuperada a níveis de pré-operação, depois da cerebelectomia. Outros déficits cerebelares foram compensados mais rapidamente e completamente nas espécies filogeneticamente mais evoluídas; primeiro o macaco, depois o guaxinim e por último o gato.

Levando em conta suas descobertas, os autores aceitaram a opinião de que o cerebelo deveria ser visto como um computador para uma análise contínua de posição e movimento, em vez de um centro em seu mais imutável sentido, como imaginavam.

Para Reis (1975), em dissertação de mestrado intitulada: Considerações Macro e Microscópicas sobre o Encéfalo de Sagüí (Callithrix jacchus, Linnaeus 1758), o cerebelo do Sagüi apresenta uma porção mediana, o verme cerebelar, muito desenvolvido, e duas expansões laterais, os hemisférios cerebelares. Apresenta, ao exame macroscópico, poucas fissuras. A fissura posterolateral, bem evidente mas pouco profunda, permite distinguir no 
cerebelo do Sagüi, o corpo cerebelar do lobo floculonodular. O lobo floculonodular compreende os flóculos direito e esquerdo, bem demarcados e unidos ao nódulo pelos seus respectivos pedúnculos. Estão situados na face caudal do respectivo hemisfério cerebelar, junto ao pedúnculo cerebelar médio. O nódulo é impar, dispõe-se medialmente e é bem desenvolvido. No corpo do cerebelo há um sulco profundo, a fissura primária, que divide o corpo cerebelar numa porção cranial (anterior) e outra caudal (posterior). A porção cranial é a parte do cerebelo situada cranialmente à fissura primária. Suas formações medianas, observadas através de cortes sagitais medianos, apresentam-se contínuas umas às outras. Podem-se, todavia, notar folhas cerebelares correspondentes à língula, bem como folhas cerebelares correspondentes ao cúlmen. As formações hemisféricas da porção cranial do cerebelo são pouco desenvolvidas e não apresentam lobulação.

Na porção caudal, situada entre as fissuras primárias e posterolateral, as formações medianas, pirâmides e úvula destacam-se pelo seu desenvolvimento. São proeminentes quando se examina a face caudal do cerebelo. A tonsila apresenta-se bastante rudimentar. Nota-se, ainda, entre a pirâmide e a úvula, a presença da fissura secundária. As demais formações medianas, declive, folha e túber, apresentam-se sem separação nítida. As expansões hemisféricas da porção caudal são, também, de pouca expressão; não apresentam fissuras e as folhas cerebelares correspondentes ao lóbulo quadrangular, em sua porção caudal, e aos lóbulos semilunares, não tendo delimitação nítida. Os três pares de pedúnculos cerebelares, caudal, médio e cranial são bem individualizados.

Microscopicamente foram descritos os núcleos denteados e possivelmente os fastigiais, além de células dos núcleos globoso e emboliforme. 
Voogd (1975), em trabalho a respeito da divisão do cerebelo dos mamíferos, argumenta que o cerebelo mostra uma divisão constante em um número de regiões mais ou menos independentes (centros de crescimento) e que cada região consiste em um conjunto de folhas paralelas separadas por um sulco transverso.

A aplicação indiscriminada da nomenclatura do cerebelo humano nas investigações anatômicas comparativas era descartada.

No cerebelo de Lemur albifrons, o sulco primário foi reconhecido como a fissura mais profunda em uma secção sagital mediana do cerebelo. Alguns dos sulcos transversais do lobo anterior podem ser localizados na sua margem lateral, pois os outros somente estão presentes na parte mediana. Não foi encontrada nenhuma indicação do sulco paramediano delimitando o verme neste lobo.

O lobo posterior pode ser dividido em uma pequena parte rostral, de organização simples e outra, maior, que consiste do lóbulo mediano posterior e lóbulos laterais posteriores pareados. O lóbulo simples mostra algumas características como o lobo anterior; os sulcos paralelos são contínuos da região medial para as laterais. Na maioria dos mamíferos este lobo não possui uma divisão entre verme e hemisférios.

Caudalmente ao lóbulo simples e profundamente ao sulco paramediano que divide o lóbulo de organização mais complexa em verme e hemisférios, o verme, lobo posterior mediano de Bolk, consiste em uma longa cadeia de folhas estreitas.

A disposição das folhas do lobo lateral posterior mostra uma característica diferente, ambas nas partes rostral e caudal, apresentando-se em curvas. A curvatura rostral do lóbulo 
ansiforme de Bolk inicia-se no centro da curva do sulco intercrural, separando duas partes contínuas, os pilares I e II do lóbulo ansiforme.

Nos cerebelos de antropóides, os lóbulos ansiforme e paramediano geralmente consistem de folhas longas e a mudança na disposição das folhas na transição entre estes dois lóbulos é menos visível. Nestes casos, foram chamados de lóbulos ansoparamedianos. Morfologicamente, o lóbulo paramediano mostra menos variações e a posição do lóbulo mediano posterior facilita a determinação das relações entre verme e hemisférios, nesta parte do cerebelo.

No lobo mediano posterior, foram distintos três lóbulos $\mathrm{A}, \mathrm{B}$ e $\mathrm{C}$ em todos os mamíferos. Os lóbulos $\mathrm{A}$ e $\mathrm{B}$ correspondem respectivamente ao nódulo e à úvula do cerebelo humano.

O lóbulo $\mathrm{C}$ foi dividido em caudal $\mathrm{C} 1$, correspondendo à Pirâmide e rostral $\mathrm{C} 2$, correspondendo ao declive, folha e túber do cerebelo humano. Os lóbulos C1 e C2 estão separados por um sulco pré-piramidal profundo, que algumas vezes pode ser localizado no lóbulo paramediano, mas nunca forma uma extremidade entre os lóbulos Ansiforme e Paramediano.

No lóbulo simples as relações entre a parte rostral do lóbulo $\mathrm{C} 2$ e o hemisfério não são muito desenvolvidas, pois em muitos mamíferos é impossível qualquer separação em verme e hemisfério nessa região. Em mamíferos com o lóbulo ansiforme bem desenvolvido, a parte caudal do lóbulo $\mathrm{C} 2$ e do hemisfério eram descontínuas.

As folhas da parte rostral da pirâmide depõem-se lateralmente e formam um pendulo que passa caudalmente ao lóbulo paramediano, terminando em posição adjacente com a primeira folha do paraflóculo. 
As partes mais caudais da série de folhas do verme e do hemisfério parecem ser completamente independentes umas das outras. Na subdivisão do cerebelo de mamíferos, três regiões tinham um grau diferente de continuidade entre as camadas de folhas do verme e hemisférios. No lobo anterior e no lóbulo simples esta continuidade é completa e não há razão para se diferenciar o verme, dos hemisférios. Na parte rostral do lóbulo de organização mais complexa, a continuidade dos lóbulos ansiforme, do lóbulo paramediano e do lóbulo C mostra uma variação característica entre as diferentes espécies. Na parte caudal desse lóbulo, o sulco inter e intralobular dos lóbulos A, B e o verme são sempre descontínuos.

Segundo a divisão funcional do cerebelo, no lobo anterior e lóbulo simples está concentrada a coordenação bilateral dos músculos da cabeça e pescoço (músculos dos olhos, da mastigação, faciais e laríngeos). Os pilares I e II do lóbulo ansiforme e os lobos paramedianos contêm centros relacionados aos membros anteriores e posteriores. Um centro para os movimentos sinérgicos das extremidades está presente na parte correspondente ao lóbulo C2 do verme. Em mamíferos, com uma abdução da partes distal dos membros (Perissodactilos), o lóbulo C2 é maior e cheio de curvas, enquanto o lóbulo ansiforme é pouco desenvolvido.

Em mamíferos com um grau mais alto de liberdade de movimentos dos membros, a relação recíproca entre o verme e o hemisfério é invertida e o lóbulo ansiforme mostra um desenvolvimento progressivo. Aqui os movimentos são coordenados por dois centros separados que melhoram a compensação para mudanças de equilíbrio.

A coordenação dos músculos do membro pélvico e da cauda foi atribuída às partes caudais do verme e hemisférios, mas hesitou em obter maiores informações sobre suas 
relações funcionais. As zonas do verme controlam a postura, o tônus, a locomoção e o equilíbrio do corpo inteiro, funcionalmente em rigorosa sinergia com a porção extrapiramidal do cérebro. As zonas paravermais controlam a condição de postura e reflexos de salto, tônus e movimentos individuais dos membros ipsilaterais e, funcionalmente, em correspondência com a parte piramidal do cérebro.

Swindler e Wood (1982), autores de Atlas de Anatomia Macroscópica de Primatas, Babuíno, Chimpanzé e Homem, citam que o cerebelo está dividido em três lobos principais - anterior, médio e posterior, sendo similarmente disposto no Babuíno, Chimpanzé e Homem. Em Papio o lobo flocular é relativamente maior e o lobo petroso projeta-se da margem anterolateral do parafloculo.

Watanabe (1982), no trabalho intitulado Estudo Comparativo da Medula Oblonga, Ponte, Mesencéfalo e Cerebelo de Cebus apella, afirma que o cerebelo desse animal apresenta o verme cerebelar e dois hemisférios cerebelares bem desenvolvidos, com o sulco posterolateral marcado, separando o corpo do cerebelo do lobo floculonodular, que é bem desenvolvido.

O corte sagital mediano do verme cerebelar mostra claramente a fissura primária entre os lobos cranial e caudal. O lobo cranial é formado pela língula, o lobo central e o cúlmen do cerebelo, que correspondem às seguintes partes no hemispério: Asa do lóbulo central e lóbulo quadrandular anterior. O lóbulo quadrangular posterior é formado pelo declive, folium, tuber, pirâmide e úvula no verme cerebelar, correspondendo ao lóbulo simples, lóbulos semilunares superior e inferior, lóbulo biventre e tonsilas, no 
hemisfério. Os pedúnculos craniais, médios e caudais são bem desenvolvidos.

Afirma ainda que as fissuras e folhas lembram o cerebelo humano, contudo com disposição mais simples e que o desenvolvimento das formações cerebelares no Cebus são conspícuas, com verme e hemisférios cerebelares bem identificados. Em sua pesquisa foram identificados quatro grupos de núcleos: denteado, emboliforme, globoso e fastigial, bem marcados e similares aos do homem.

As folhas e fissuras são perfeitamente definidas. Quanto ao aspecto interno, as folhas e a substância branca com os núcleos cerebelares estão bem diferenciados. Os núcleos denteado, emboliforme, globoso e fastigial são desenvolvidos, similares aos de Calithrix. Os mesmos núcleos no Homem são mais evoluídos e melhor delimitados.

Romer e Parsons (1985), em Anatomia Comparada dos Vertebrados afirmam, de modo geral, que em todos os vertebrados, assim como nos invertebrados de organização mais complexa, encontramos uma concentração de tecido nervoso na extremidade anterior do corpo, formando o encéfalo ou uma estrutura cerebral correspondente. Sendo esta a região que primeiramente entra em contato com os estímulos ambientais, é onde se situam as principais estruturas sensoriais.

Primitivamente, o encéfalo dos vertebrados era uma região anterior pouco desenvolvida do tubo neural, permitindo reflexos locais da cabeça e região faríngea, além de reunir estímulos sensoriais especiais que dali eram encaminhados para o restante do corpo através da medula espinhal, como no anfioxo. Nos vertebrados, ocorreu uma forte tendência de concentração do comando das funções do corpo no encéfalo, exceto os reflexos mais simples, com o desenvolvimento de centros complexos e intercomunicantes. 
Segundo estes autores o cerebelo é um centro do encéfalo, freqüentemente de grande tamanho, que tem extrema importância na coordenação e na regulação de atividades motoras e na manutenção da postura, atuando passivamente, de forma reflexa, na manutenção do equilíbrio e na orientação corporal. Um comando dos hemisférios ou do teto para uma ação muscular, como a do movimento de uma perna, não pode ser eficientemente efetuado a não ser que existam dados referentes à posição e ao movimento real da perna, sobre o estado de relaxamento ou de contração dos músculos envolvidos, sobre a posição geral do corpo e sobre sua relação com o mundo exterior.

Os dados com os quais o cerebelo atua são derivados da área vestibular do bulbo, área vestibular lateral dos vertebrados primitivos, na qual são registradas sensações do ouvido e da linha lateral, referentes ao equilíbrio. Outra fonte é o sistema de feixes musculares e tendões, no qual suas fibras são dirigidas ao cerebelo, transmitindo dados sobre a posição de partes do corpo e sobre o estado de tensão dos músculos.

Nos animais em que o cerebelo é bem desenvolvido, os tratos de fibras que se dirigem para ele e dele emergem para outros locais, são importantes na arquitetura do tronco encefálico, como nos mamíferos, nos quais estas fibras formam três pares de pedúnculos cerebelares.

O cerebelo varia de tamanho e forma, conforme o grupo. Seu grau de desenvolvimento está correlacionado com a complexidade dos movimentos do corpo; é grande e elaborado em muitos peixes, aves e mamíferos, pequeno em répteis e pouco desenvolvido em ciclóstomos e anfíbios. Os flóculos persistem em todos os grupos, estando relacionados com o equilíbrio e intimamente conectados com o ouvido interno, contudo, 
mesmo nas lampreias existe algum desenvolvimento de uma região cerebelar mediana entre os flóculos.

O corpo cerebelar constitui a principal massa do cerebelo em peixes típicos, répteis e aves. Nos mamíferos, o córtex cerebral comandando as funções motoras e o desenvolvimento de grandes tratos que vão e voltam do córtex motor até o cerebelo, estão correlacionados com o aparecimento dos hemisférios cerebelares. O cerebelo é uma região na qual a substancia celular cinzenta se dispõe superficialmente como um córtex laminado, ficando a substância branca no interior.

Getty (1986), na obra Anatomia dos Animais Domésticos, afirma que o cerebelo no eqüino é um órgão globular, de formato irregular, ligeiramente comprimido rostro-caudalmente, com seu diâmetro maior no eixo transverso, situando-se na fossa caudal do crânio e, cobrindo inteiramente a fossa rombóide, os colículos rostral e caudal, os pedúnculos cerebelares rostrais, sobrepondo-se às bordas laterais da medula oblonga. Sua borda e parte da superfície rostral são cobertas pelos lobos occipitais cerebrais.

A fissura primária subdivide o corpo do cerebelo nos lobos rostral e caudal. O primeiro pode ser subdividido em uma pequena e estreita língua, representando a parte mais rostral do verme, no lóbulo central, maior, subdividido em duas partes e cúlmen, também subdividido em duas partes.

Referindo-se à nomenclatura utilizada, o autor afirma que a versão clássica baseava-se essencialmente nas investigações anatômicas humanas, até que foram substituídas por subdivisões e nomenclaturas que são mais universalmente aplicáveis também a outras espécies. Assim, o lobo rostral pode ser dividido em vínculo da língula, asa do lóbulo central e lóbulo quadrangular. 
O lobo caudal do cerebelo do eqüino é caracterizado por extrema variabilidade morfológica. O verme está subdividido rostro-caudalmente em declive, folha do verme e túber do verme. Os lóbulos simples, ansiforme e paramediano são os lóbulos correspondentes nos hemisférios.

A parte floculonodular do lobo caudal consiste no nódulo, mediano, na extremidade caudal do verme e os flóculos, laterais. Filogeneticamente este lobo é a parte mais antiga do cerebelo, relacionando-se exclusivamente ao aparelho vestibular, encontrando-se separado do lobo caudal pela fissura caudolateral.

O cerebelo dos ruminantes foi descrito ocupando a área entre a medula oblonga e o cérebro, estando parcialmente encoberto pelos lobos occipitais dos hemisférios cerebrais. Nestes animais o órgão cobre a parte caudal do colículo rostral e o colículo caudal do mesencéfalo, que se encaixam em denteações na superfície rostral do cerebelo.

Os hemisférios do cerebelo sobrepõem-se, em grande parte, às bordas laterais da medula oblonga. A superfície deste órgão é bastante irregular e, nos grandes ruminantes o verme não é muito proeminente, embora seja facilmente reconhecido. Suas folhas são muitas vezes contínuas com as folhas dos hemisférios laterais, que se apresentam comprimidos rostrocaudalmente, com sua superfície rostral achatada, adaptando-se à porção caudomedial dos hemisférios cerebrais.

A superfície caudal do cerebelo dos ruminantes está subdividida em muito mais lóbulos e é mais irregular do que a rostral.

Nos pequenos ruminantes, o verme é mais proeminente e mais claramente separado dos hemisférios laterais, que são planos e lisos em suas superfícies rostrais, apresentando-se irregulares e subdivididos em lobos e lóbulos nas superfícies caudais. 
A fissura primária separa o cerebelo em lobos rostral e caudal. O primeiro é composto pela língula, um pequeno lóbulo entre os pedúnculos cerebelares que está coberto ventralmente pelo véu medular rostral, lóbulo central e pelo cúlmen, um lóbulo muito proeminente e bem definido, seguido caudalmente pelo declive, um lóbulo um tanto longo, cujas folhas são contínuas com as folhas dos hemisférios. Todos os demais lóbulos do lobo caudal são bem separados dos hemisférios por um sulco profundo. A folha do verme e o túber do verme são de contornos mais irregulares.

A pirâmide, quase exclusivamente retangular, é seguida pela úvula, que está em contato com o plexo corióide do quarto ventrículo e, cuja extremidade rostral toca a parte caudal da língula.

A região mais caudal do verme é conhecida como nódulo e, juntamente com os flóculos, laterais, forma o lobo floculonodular do cerebelo.

No suíno, o cerebelo é uma estrutura muito larga com grandes hemisférios laterais que se estendem em sua maioria, além das bordas laterais da medula oblonga. Topograficamente, está intimamente relacionado com a superfície cerebelar do hemisfério cerebral.

A totalidade da superfície rostral do órgão está subdividida em folhas, que são contínuas do verme até os hemisférios. Partes das superfícies rostral e caudal são muito mais irregulares e estão subdivididas em lobos e lóbulos.

A fissura primária é profunda, dividindo o cerebelo em metades rostral e caudal, claramente reconhecíveis devido a disposição regular das folhas na parte rostral e pela disposição irregular na parte caudal. A língula, o lóbulo central e o cúlmen compõem a 
parte rostral do verme e, os dois primeiros estão em contato com o véu medular rostral e lâmina do tecto do mesencéfalo.

O cúlmen é seguido caudalmente pelo declive, a folha, irregular e muitas vezes proeminente, túber do verme, pela pirâmide, que continua dentro da língula. O nódulo constitui a parte mais rostral desta região do verme.

Nos carnívoros o cerebelo foi descrito como um órgão de formato irregular, situado entre os hemisférios cerebrais e a medula oblonga, com maior diâmetro na direção medial lateral, apresentando-se ligeiramente comprimido numa direção ventrocaudal e, com o verme e os hemisférios bem desenvolvidos.

A superfície rostral do cerebelo, dado o seu íntimo relacionamento topográfico com os hemisférios cerebrais, é um tanto regular e lisa, enquanto a superfície caudal está sujeita a maior variação morfológica.

A fissura primária é profunda, separando o cerebelo em lobos rostral e caudal, situando-se ao nível de um plano frontal através do ponto mais caudal do lobo occipital do cérebro. A língula, o lóbulo central e o cúlmen são constituintes do lobo rostral. O declive, o túber, a folha, a pirâmide e a úvula do verme, com sua parte mais rostral, e o nódulo são as subdivisões do lobo caudal.

O nódulo e o flóculo formam o lobo floculonodular, que está associado ao aparelho vestibular. O flóculo é a parte mais ventral do hemisfério do cerebelo, localizado dorsalmente à origem do nervo trigêmio.

Rostrolateralmente ao flóculo encontra-se o paraflóculo, formado por duas partes alongadas em direção rostrocaudal, cada uma das quais mais uma vez subdividida em numerosas folhas. A porção dorsal está relacionada rostralmente com a parte lateral do 
lóbulo simples, centralmente ao lóbulo ansiforme e caudalmente ao lóbulo paramediano. Este último, com suas folhas orientadas na mesma direção que as folhas do verme, situa-se lateralmente à úvula do verme, a pirâmide e ao túber do verme, sendo contínuo, lateralmente, ao lóbulo ansiforme. Este último estende-se lateralmente, e, em sua extremidade lateral, rostralmente, para circundar a borda caudolateral do lóbulo simples.

Os núcleos cerebelares profundos estão circundados pela medula e podem ser divididos em núcleo cerebelar lateral (denteado), núcleo interposto lateral, núcleo interposto medial e núcleo do fastígio.

Para Noback et al. (1999), na obra Neuroanatomia. Estrutura e Função do Sistema Nervoso Humano, o cerebelo coordena a ação muscular inconsciente, sincronizando as contrações individuais e entre grupos musculares, uniformizando suas respostas através da regulação da tensão, sendo desta forma, importante também no equilíbrio e tonicidade muscular.

Este órgão está localizado na fossa posterior do crânio, abaixo da tenda do cerebelo e sobremontando a ponte e o bulbo, sendo constituído por uma camada externa de substância cinzenta (córtex), um corpo medular de substância branca, quatro pares de núcleos profundos [Fastigial, Interpósito posterior (globoso), Interpósito anterior (emboliforme) e denteado]. Os núcleos globoso e emboliforme podem ser chamados de núcleo interposto.

O cerebelo está ligado ao tronco encefálico pelos pedúnculos cerebelares superior, médio e inferior.

O cerebelo pode ser subdividido antimericamente em dois hemisférios, separados por um verme estreito; transversalmente, em lobo floculonodular, lobo anterior e 
lobo médio ou posterior. De acordo com outro enfoque, pode ser dividido em zona mediana (do verme), zona intermédia e zona lateral ou hemisférica.

Lent (2001), no livro Cem Bilhões de Neurônios: Conceitos Fundamentais de Neurociência, relata a descoberta recente de que o cerebelo humano apresenta aumento no fluxo sangüíneo durante a execução de tarefas motoras como a linguagem, aprendizagem de movimentos complexos, movimentos com conteúdo emocional, entre outras. Cita ainda seu envolvimento com a capacidade mental do indivíduo, visto que autistas e esquizofrênicos freqüentemente apresentam lesões cerebelares.

Didio (2002), em Tratado de Anatomia Sistêmica Aplicada, relata a existência, no ser humano, de sete fissuras cerebelares: Primária, que separa o lobo superior do inferior, localizada entre o cúlmen e o declive do verme e entre o lóbulo quadrangular e o lóbulo simples, no hemisfério; Secundária, entre a úvula e a pirâmide do verme e entre o lóbulo biventre e a tonsila, no hemisfério; Pósterolateral, que divide o cerebelo em corpo e lobo floculonodular, separando também o nódulo da úvula no verme e o flóculo da tonsila no hemisfério; Horizontal, que separa o túber da folha do verme e o lóbulo semilunar superior do inferior no hemisfério; Pré-Central, entre o lóbulo central e a língula, no verme; Pré-Culminal, entre o cúlmen e o lóbulo central no verme e entre a parte anterior e posterior do lóbulo quadrangular; Pós-Clival, entre a folha e o declive no verme e o lóbulo semilunar superior e a parte posterior do lóbulo quadrangular no hemisfério. 
Segundo Machado (2002), em sua obra Neuroanatomia Funcional, o cerebelo do homem contribui para a formação do tecto do IV ventrículo, repousando sobre a fossa cerebelar do osso occipital e ligando-se à medula e ao bulbo pelo pedúnculo cerebelar inferior e à ponte e mesencéfalo pelos pedúnculos cerebelares médio e superior, respectivamente.

A superfície do cerebelo apresenta sulcos de direção predominantemente transversal, que delimitam lâminas finas denominadas folhas do cerebelo. Existem também sulcos mais profundos, as fissuras do cerebelo, que delimitam lóbulos, cada um deles podendo conter várias folhas.

A divisão do cerebelo em lóbulos não tem significado funcional, apenas topográfico, sendo a nomenclatura dos lóbulos e fissuras bastante confusa, havendo divergências entre os autores.

O mesmo autor cita ainda que o estudo dos lóbulos do cerebelo deve ser feito preferencialmente em peças em que o verme é seccionado sagital e medianamente, permitindo uma identificação mais precisa das fissuras. 


\section{MATERIAL E MÉTODO}

Foram utilizados neste trabalho 20 espécimes de Cebus apella (macacoprego), constantes do acervo de pesquisa do Prof. Dr. Zenon Silva, na Universidade Federal de Uberlândia, MG, sendo 16 deles para estudos macroscópicos e 04 para estudos de cortes, em lâminas.

Os animais foram conservados em solução aquosa de formol a 10\%, em cubas de paredes opacas que evitam a penetração de luz, e conseqüente degradação do formaldeído.

Foi efetuada a dissecação da região de interesse, observando-se todas as estruturas macroscópicas e acidentes, nomeando-os de acordo com a nomenclatura adotada, ou seja, Terminologia (2001).

Procedeu-se à feitura de secções segundo os planos horizontal e sagital mediano, com aproximadamente $2 \mathrm{~mm}$ de espessura, manualmente, com navalha de micrótomo, sendo coradas pelas soluções de Mulligan, conforme método de Rodrigues, 1973.

Todo o material estudado foi documentado por fotografias, para melhor compreensão de sua estrutura e os dados encontrados foram comparados com descrições para a espécie humana, para animais da família cebidae e de outros mamíferos, a fim de se elucidarem possíveis e prováveis semelhanças e/ou diferenças entre o cerebelo de outras espécies e o do macaco Cebus apella. 


\section{RESULTADOS}

\subsection{ASPECTOS MORFOLÓGICOS DA SUPERFÍCIE EXTERNA}

O cerebelo do macaco Cebus apella situa-se posteriormente ao tronco encefálico, inferiormente ao lobo occipital, recoberto por este em quase toda a sua extensão. Contribui para a formação do teto do quarto ventrículo e encontra-se ligado ao bulbo, ponte e mesencéfalo pelos pedúnculos cerebelares inferior, médio e superior, respectivamente (Figuras 1 a 4).

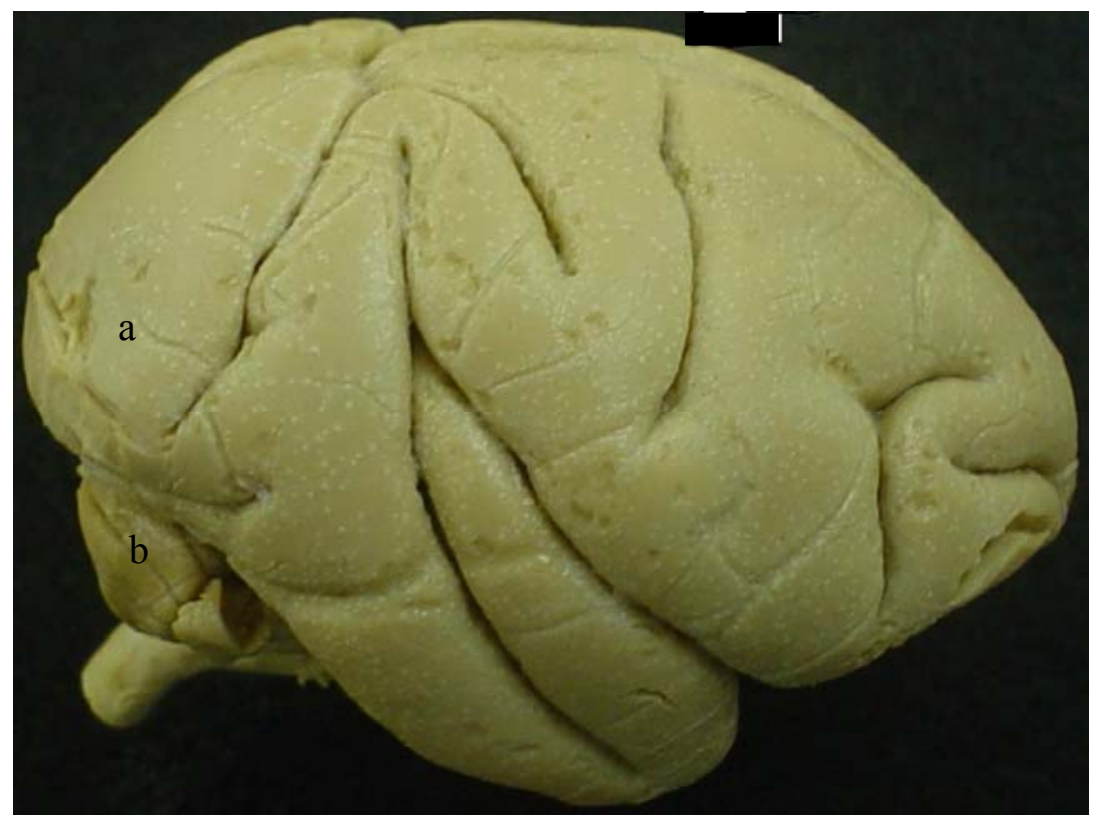

Figura 1- Encéfalo de Cebus apella em vista lateral direita, evidenciando-se a maneira como os lobos occipitais do cérebro (a) recobrem parte do cerebelo (b) 


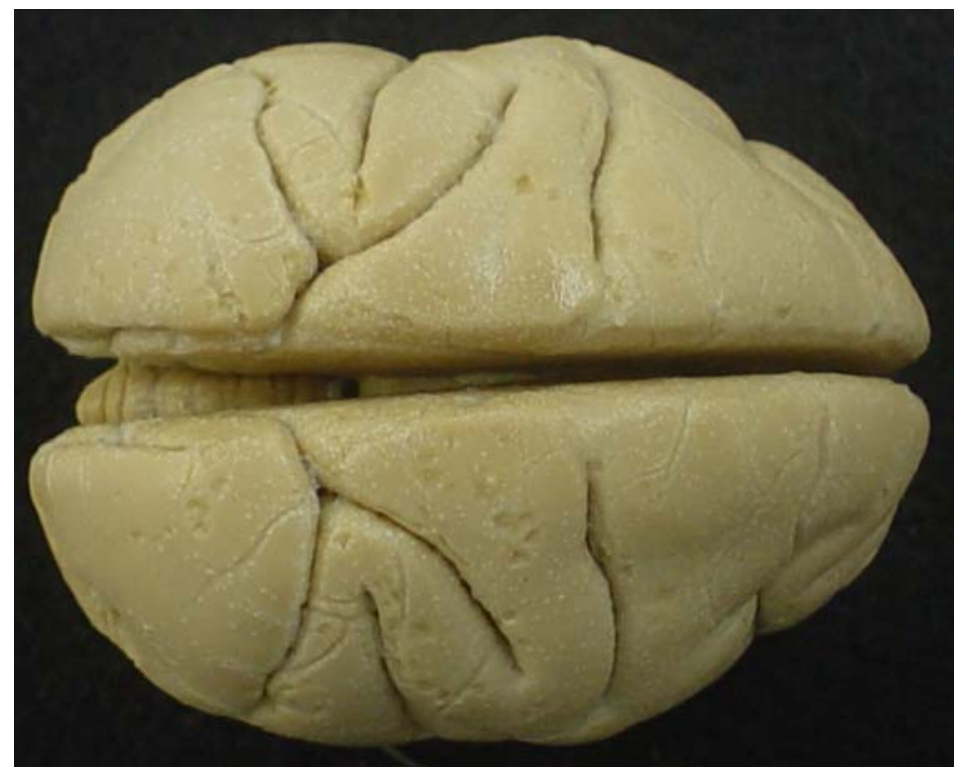

Figura 2 - Encéfalo de Cebus apella, em vista superior, evidenciando-se o cerebelo na profundidade da fissura mediana do cérebro

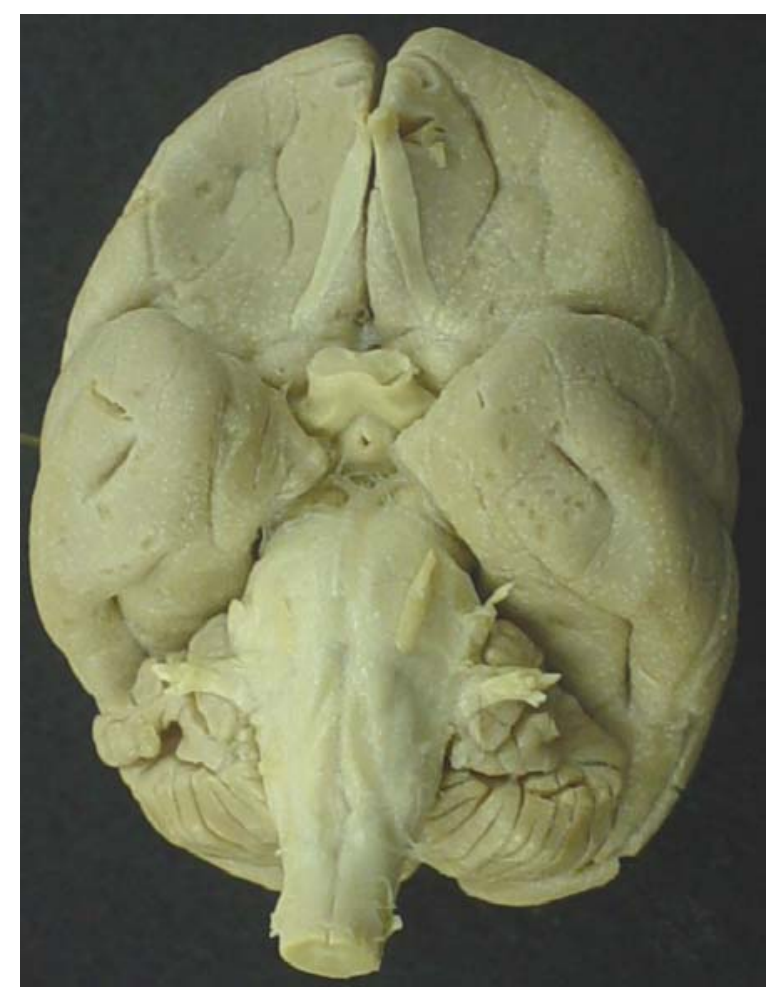

Figura 3 - Encéfalo de Cebus apella, em vista inferior, evidenciando-se a relação cerebelo-tronco encefálico-cérebro 


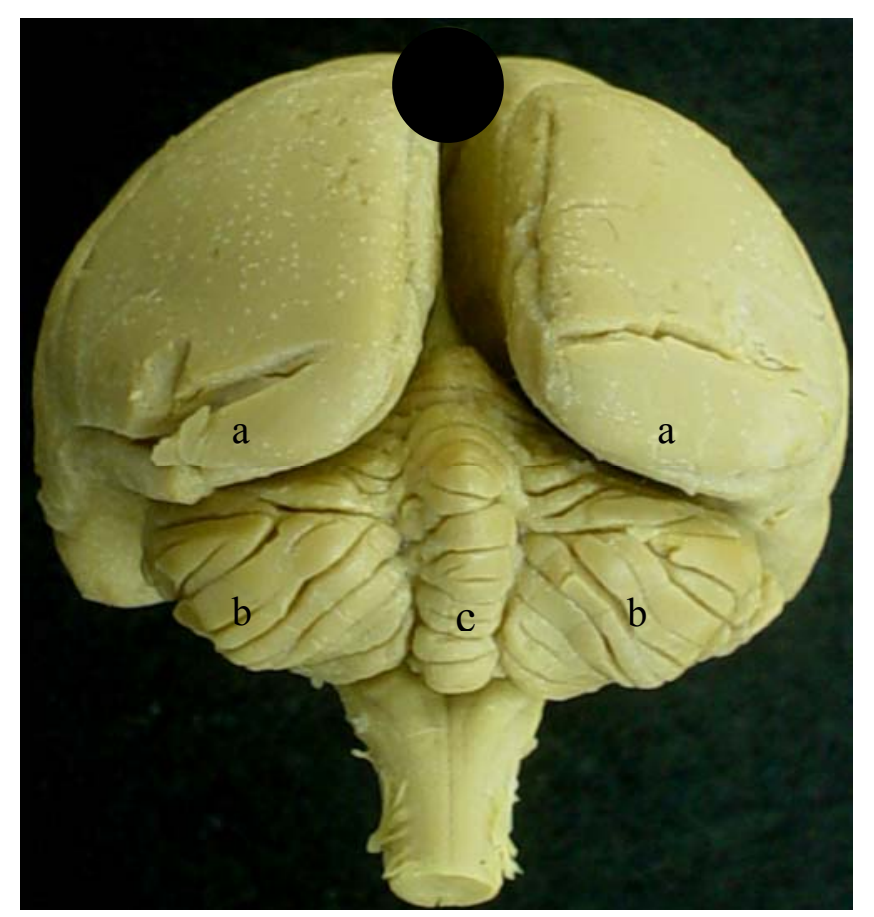

Figura 4 - Encéfalo de Cebus apella, em vista posterior, evidenciando-se a maneira como os lobos occipitais do cérebro (a) recobrem parcialmente os correspondentes hemisférios cerebelares (b). Observa-se ainda a particular disposição do verme do cerebelo (c)

Estruturalmente, o cerebelo é composto por uma cobertura superficial de substância cinzenta, o córtex do cerebelo, e uma massa branca compacta, interna, o corpo medular, além de quatro pares de núcleos.

O córtex acomoda-se em várias lâminas com disposição predominantemente transversa, denominadas folhas do cerebelo e, na substância branca, alojam-se os núcleos.

Em vista superior, o cerebelo apresenta um verme bastante desenvolvido em relação aos dois hemisférios, marcado por sulcos transversais paralelos. Em cada antímero, lateralmente ao verme, observa-se uma projeção achatada, o hemisfério cerebelar (Figuras $5,8$ e 9$)$ 
Em vista inferior podemos reconhecer a porção inferior do verme, dividida em vários segmentos, por sulcos transversais. Nesta vista, os dois hemisférios cerebelares acham-se nitidamente separados do verme, por uma fissura mediana (Figura 10).

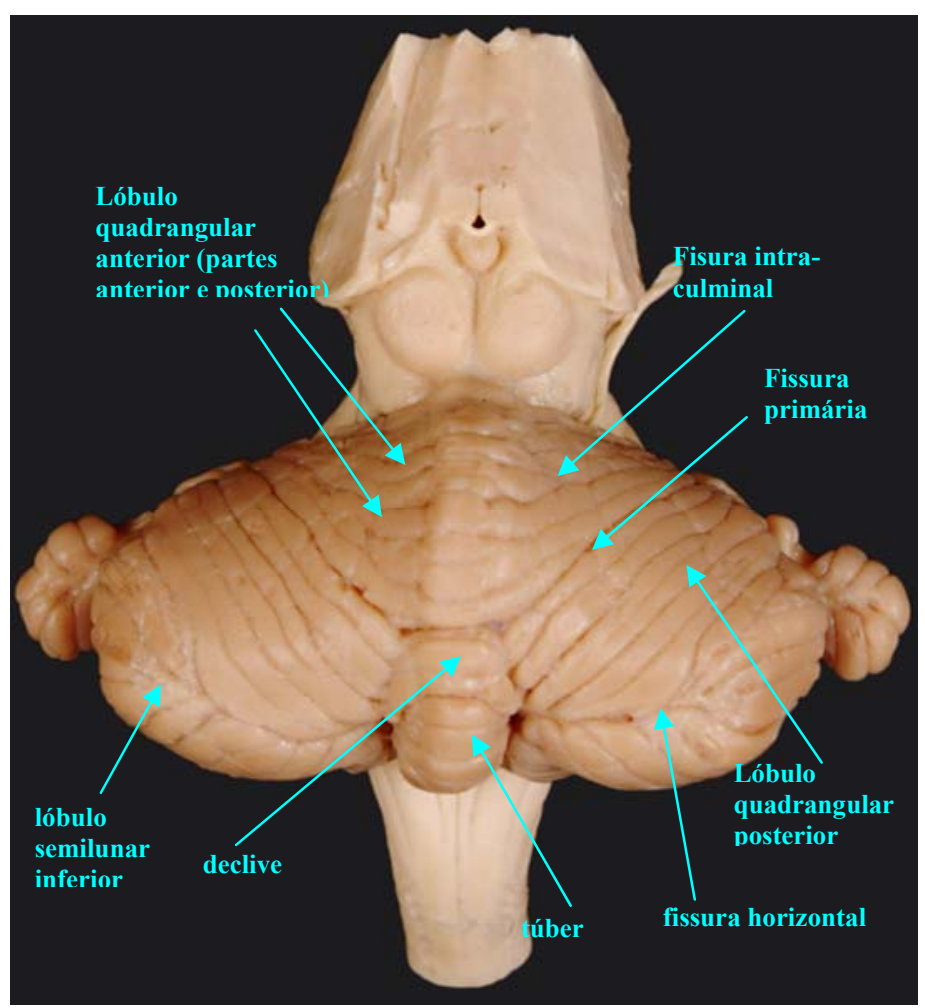

Figura 5 - Cerebelo e tronco encefálico de Cebus apella, em vista posterior, evidenciando-se o Lobo anterior e parte do Lobo Posterior do cerebelo, além das fissuras e lóbulos indicados 


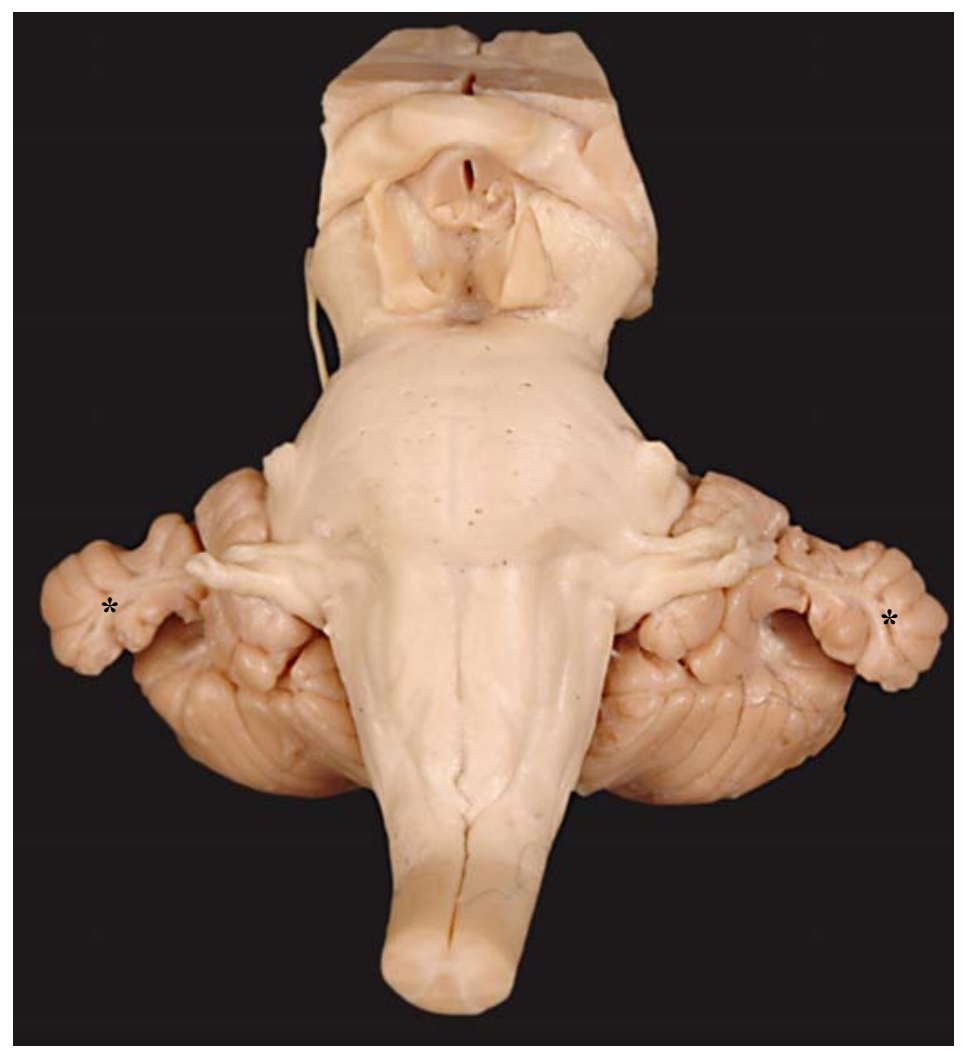

Figura 6 - Cerebelo e Tronco Encefálico de Cebus apella, em vista antero-inferior, evidenciando-se a relação ente eles bem como a localização, em ambos os antímeros, dos flóculos $(*)$, bem desenvolvidos

É possível considerar, no cerebelo do Cebus, três partes: lobo anterior, lobo posterior e lobo floculonodular, que formam seu corpo. Sua superfície apresenta sulcos que delimitam as folhas do cerebelo e sulcos mais profundos, as fissuras, que delimitam os lóbulos (Figuras 5 a 10). As folhas do verme podem apresentar-se contínuas com as dos hemisférios cerebelares. 
A consistência deste órgão quando examinado a fresco é semelhante à do cérebro, sendo que sua porção central é mais consistente. A pia-máter, bem aderida à sua superfície dificulta a dissecação do órgão para o procedimento de uma observação macroscópica minuciosa e, durante a sua retirada pode ocorrer o desprendimento de parte do córtex adjacente.

O cerebelo do Cebus apella apresenta dimensões variando de $2,7 \mathrm{~cm}$ a $4,0 \mathrm{~cm}$ para o diâmetro latero-lateral (média de $3,48 \mathrm{~cm}$ ), de $1,6 \mathrm{~cm}$ a 2,1 cm para o supero-inferior (média de $1,83 \mathrm{~cm}$ ) e de $1,5 \mathrm{~cm}$ a $2,0 \mathrm{~cm}$ para o antero-posterior (média de $1,83 \mathrm{~cm}$ ).

\subsubsection{Lobo Anterior}

Esta região, no verme, encontra-se constituída pela língula do cerebelo, pelo lóbulo central (e suas asas ou expansões laterais) e o cúlmen. Estas três porções são separadas entre si, por sulcos bem pronunciados, as fissuras pré-central e pré culminal. A primeira interpõe-se entre a língula e o lóbulo central e, a segunda, entre este lóbulo e o cúlmen (Figuras 5, 7 e 9). 


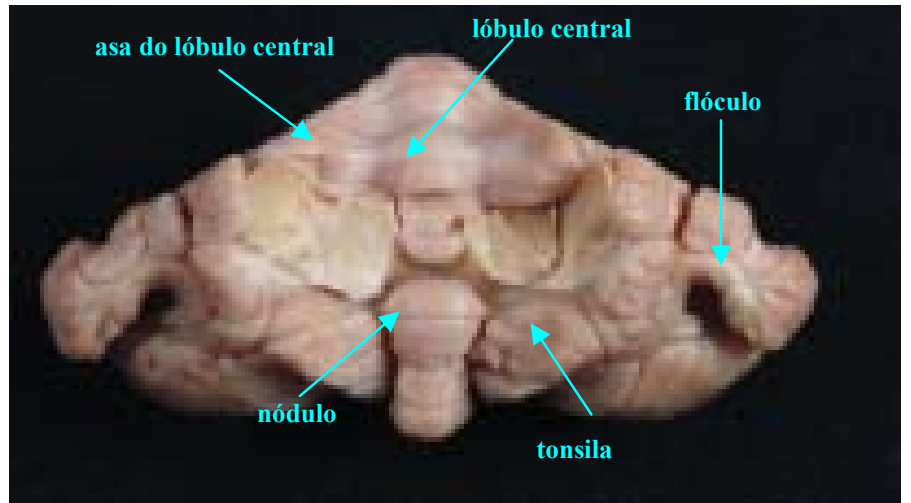

Figura 7 - Cerebelo de Cebus apella, em vista anterior, evidenciando-se as estruturas indicadas

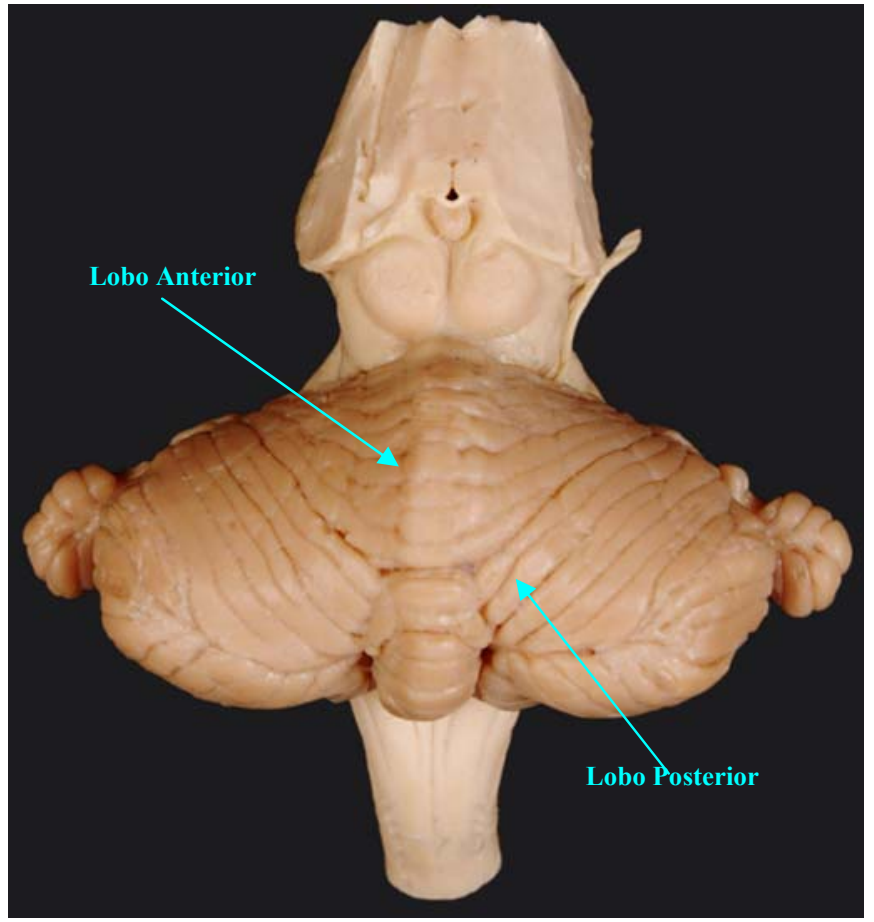

Figura 8 - Cerebelo e tronco encefálico de Cebus apella, em vista posterior, com destaque para os lobos anterior e posterior do cerebelo 
Cada uma das três partes (língula, lóbulo central e cúlmen) apresenta o seu córtex disposto em folhas, delimitadas por sulcos.

O lóbulo central apresenta três a cinco folhas e duas expansões laterais, as asas do lóbulo central, que recebem este nome pela sua semelhança a duas asas abertas. O cúlmen apresenta de sete a nove folhas, sendo a porção mais elevada do verme, encontrando-se dividido em duas porções pela fissura intraculminal (destacada em $80 \%$ dos órgãos).

A estas divisões encontradas no verme do C. apella corresponde outra, observada nos hemisférios. Um lóbulo quadrangular anterior em cada antímero, apresentando quatro a cinco folhas, delimitados pela fissura primária (bastante evidente em $80 \%$ dos órgãos analisados) que separa os lobos anterior e posterior (Figuras 5 e 9).

\subsubsection{Lobo Posterior}

O verme desta região do cerebelo encontra-se constituído pelo declive, folha do verme, túber, pirâmide e úvula (Figuras 5 e 10). Estas porções são separadas por sulcos bem pronunciados, as fissuras primária, pós-clival, horizontal, pré-piramidal e secundária (pós-piramidal). A primeira interpõe-se entre a pirâmide e o declive, a segunda entre o declive e a folha do verme, a terceira entre a folha e o túber, a quarta entre o túber e a pirâmide e, a quinta, entre a pirâmide e a úvula (Figura 5).

O declive apresenta de duas a quatro folhas, podendo ser identificado como a descida do cúlmen; a folha é composta por uma única folha; o túber apresenta de três a quatro folhas; a pirâmide, de duas a quatro folhas e, a úvula, de três a cinco folhas. 
A estas divisões no verme, correspondem outras duas observadas nos hemisférios, assim como no lobo anterior. O lóbulo quadrangular posterior encontra-se delimitado pelas fissuras primária e pós-clival (evidente em 100\% dos órgãos), apresentando de três a quatro folhas. Os lóbulos semilunares superior e inferior estão separados um do outro pela fissura horizontal (bem evidenciada em 90\% dos órgãos), apresentando duas folhas (Figuras 5 e 9). As tonsilas apresentam de três a quatro folhas, recebendo este nome pela relação com a úvula do cerebelo (em analogia às tonsilas faríngeas) e está separada do verme. O lóbulo biventre apresenta de quatro a sete folhas, relacionando-se medialmente com a úvula e tonsila e, lateralmente, com o lóbulo semilunar inferior. A fissura intrabiventre separa este lóbulo em duas porções (Figura 10).

A fissura póstero-lateral (evidente em $80 \%$ dos órgãos) separa os hemisférios do lobo floculonodular e o nódulo da úvula, no verme.

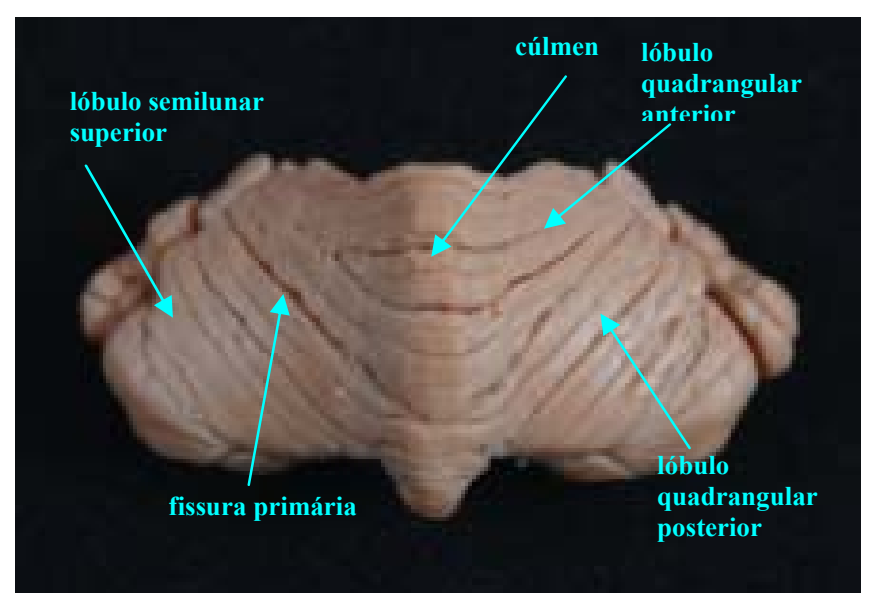

Figua 9 - Cerebelo de Cebus apella, em vista superior, evidenciando-se as estruturas indicadas 


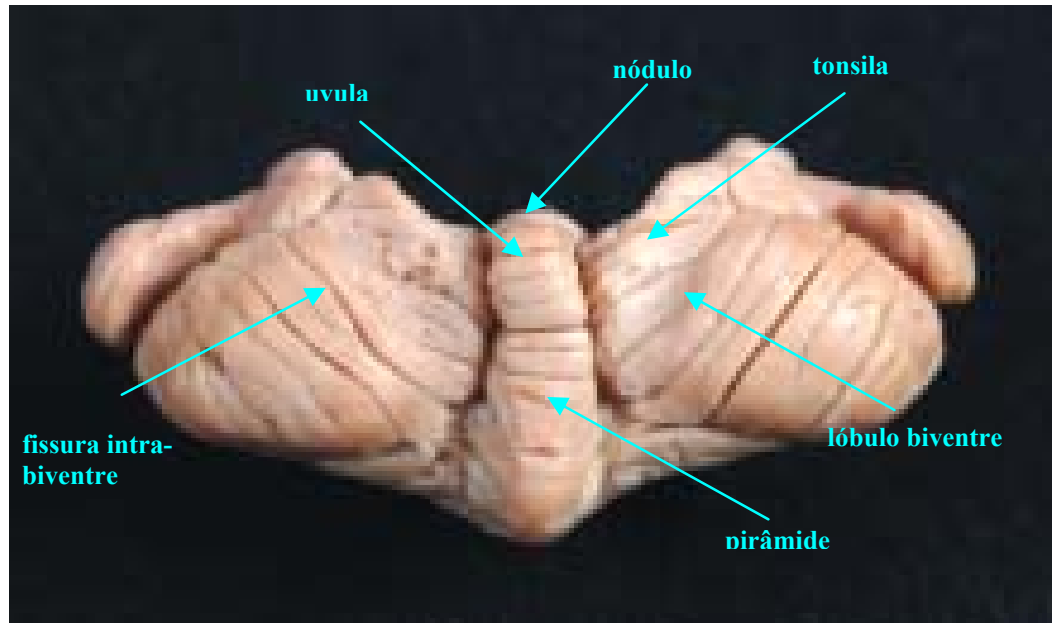

Figura 10 - Cerebelo de Cebus apella, em vista inferior, evidenciando-se as estruturas indicadas

\subsubsection{Lobo Floculonodular}

Este lobo é constituído por um flóculo direito e um esquerdo, ligados ao nódulo (que apresenta dimensões próximas às do lóbulo central) pelo pedúnculo do flóculo. O nódulo apresenta de três a cinco folhas, sendo os flóculos suas partes correspondentes, além do verme (Figuras 6 e 7).

O flóculo ocupa espaço particular dentro da cavidade craniana e apresenta dimensões variando de $0,6 \mathrm{~cm}$ a $1,5 \mathrm{~cm}$ no diâmetro latero-lateral e de $0,7 \mathrm{~cm}$ a $1,2 \mathrm{~cm}$, no diâmetro supero-inferior. 


\subsection{ASPECTOS MORFOLÓGICOS DE SUPERFÍCIE DE CORTES}

Em secção sagital mediana do cerebelo observamos o corpo medular, composto por substância branca, ocupando uma disposição central e emitindo ramos radiais, dos quais se originam ramos menores, tomando a forma dos galhos de uma árvore.

Ao redor da massa compacta de substância branca encontra-se a substância cinzenta, formadora das folhas do cerebelo (córtex cerebelar). Esta conformação, em que se visualiza, no corte sagital mediano, o córtex dispondo-se ao redor da substância branca assemelha-se ao aspecto da copa de uma árvore.

A secção horizontal do cerebelo, à altura do pedúnculo cerebelar superior permitiu a identificação, na substância branca, de quatro núcleos, que identificamos como denteado, emboliforme, globoso e fastigial.

O primeiro é o maior, apresentando o contorno irregularmente pregueado com a abertura do hilo dirigida ântero-medialmente e possuindo a porção lateral mais espessa. O segundo possui uma forma alongada, lembrando um bastão, situando-se próximo do núcleo denteado, medialmente a este.

O terceiro núcleo é o menor, formando uma massa arredondada localizada medialmente ao núcleo emboliforme. 
A coloração de Mulligan permitiu identificar uma continuidade entre as folhas do verme e as dos hemisférios, na região do cúlmen (Lobo Anterior). Nota-se também que as folhas mantem-se unidas por feixes de substância branca unidos no interior do cerebelo, formando a área mais densa do corpo medular (Figuras 11 e 12).

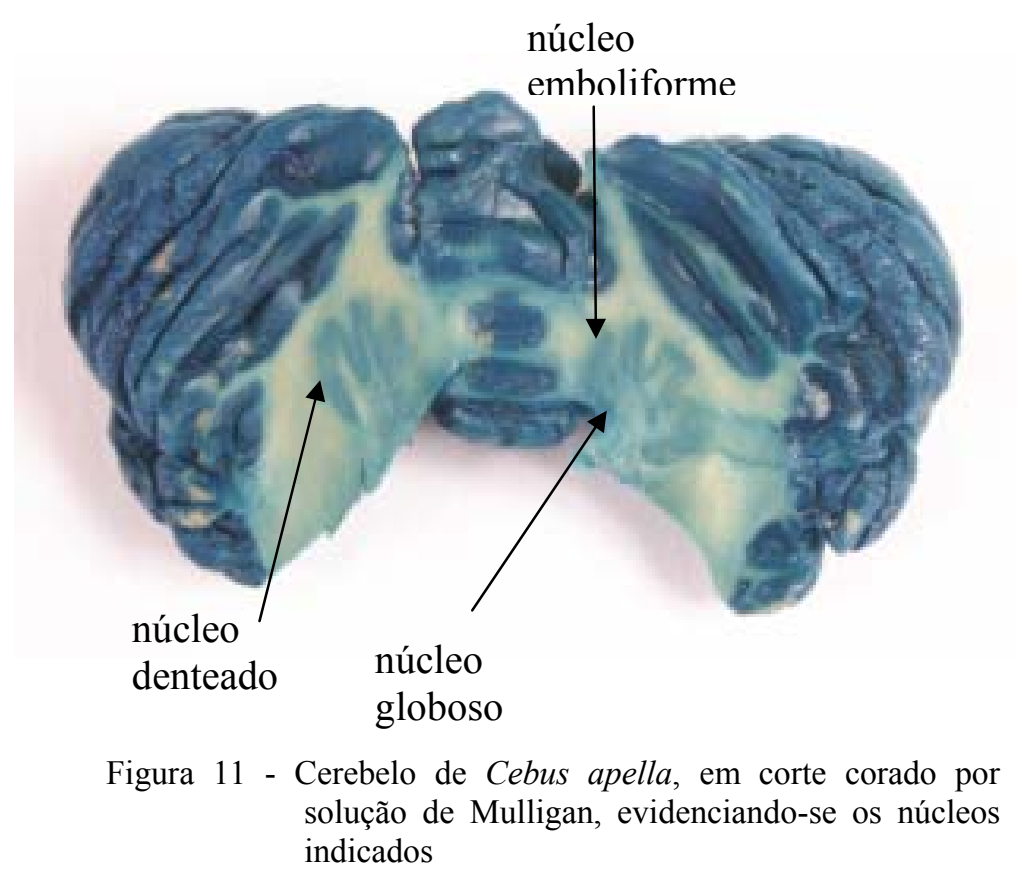




\section{DISCUSSÃO}

É assunto extremamente controvertido, o de que pesquisas científicas, que utilizam animais como objetos de estudo, sejam de suma importância para a aquisição de conhecimento e de desenvolvimento tecnológico.

Contudo, cabe aos cientistas, a consideração do direito à vida de todos os animais, objetivando a extinção de sacrifícios e de atos contestáveis como os observados no trabalho de remoção total ou parcial do cerebelo de macacos e guaxinins (WIRTH; O'LEARY, 1974).

Tanto em experimentos quanto em aulas práticas, sejam de Anatomia, Fisiologia, Cirurgia ou quaisquer outras disciplinas, a sujeição de animais a sofrimentos deve ser evitada, buscando-se métodos alternativos e substitutivos, como aulas gravadas em vídeo, por exemplo.

Em nosso trabalho, encontramos o cerebelo do Cebus apella situado posteriormente ao tronco encefálico, inferiormente ao lobo occipital do cérebro, recoberto por ele em quase toda a sua extensão, contribuindo para a formação do teto do quarto ventrículo e, ligando-se ao bulbo, ponte e mesencéfalo pelos pedúnculos cerebelares inferior, médio e superior, respectivamente.

Esta descrição está de acordo com a citada em eqüinos por Zimmerl et al. (1930) e, eqüínos, grandes ruminantes e suínos por Getty (1986), pois esses autores afirmam que o cerebelo é apenas parcialmente recoberto pelos lobos occipitais do cérebro. 
Em vista superior, o cerebelo apresenta um verme bastante desenvolvido em relação aos hemisférios, dividido por sulcos transversais paralelos. Em cada antímero lateralmente ao verme, observa-se uma projeção achatada, o hemisfério cerebelar.

Esses aspectos também foram observados por Watanabe (1982) em C. apella. Zimmerl et al. (1930) apresentam uma descrição semelhante, porém destacando que nos eqüinos os hemisférios são arredondados.

Outros autores também apresentam relatos semelhantes ao nosso, mas, discordam quanto à proeminência do verme, nas espécies estudadas, ou seja, mamíferos em geral (VOOGD, 1975), eqüinos, grandes ruminantes e suínos (GETTY, 1986) e homem (DIDIO, 2002; MACHADO, 2002).

O cerebelo dos carnívoros e dos pequenos ruminantes apresenta um verme proeminente, mas com a superfície rostral lisa (GETTY, 1986), enquanto no cerebelo de Callithrix jacchus, o verme apresenta-se proeminente, mostrando-se pouco dividido por fissuras (REIS, 1975).

Em nosso material, o verme proeminente e a divisão em lobos, como nos carnívoros, pequenos ruminantes e Callithrix jacchus podem ser explicados evolutivamente pelo fato de que todos pretencem à mesma classe (mamalia), devendo apresentar características semelhantes, sobretudo no que diz respeito ao sistema nervoso central.

Contudo, a maior lobulação do cerebelo do C. apella deve estar relacionada com o fato deste espécime apresentar a capacidade de realizar movimentos mais complexos e delicados como abrir e fechar torneiras, trincos de portões, usar objetos como ferramentas e assumir postura semi-ereta grande parte do tempo. 


\subsection{LOBO ANTERIOR}

Encontra-se constituído, no verme, por língula do cerebelo, lóbulo central (e suas asas ou expansões laterais) e cúlmen, separados pelas fissuras pré-central e pré-culminal.

Nos hemisférios, notamos um lóbulo quadrangular anterior em cada antímero, correspondendo às estruturas do verme. A fissura primária delimita estes lóbulos, dividindo o cerebelo em lobos anterior e posterior.

Hill (1962), estudando Ateles e Voogd (1975), em seus estudos sobre a anatomia de Lemur albifrons, não relatam a presença de lobulação no verme ou hemisférios cerebelares, provavelmente devido ao fato do órgão destas espécies apresentar-se relativamente liso, apesar de a fissura primária estar presente em ambos.

Apesar dos autores não fornecerem dados que tornem possível uma comparação entre lobulação e habilidades motoras, podemos afirmar que filogeneticamente, Ateles e Lemur albifrons evoluíram divergentemente de Cebus apella, no que diz respeito ao sistema nervoso central, especificamente, o cerebelo.

O alto grau de lobulação observado em nosso trabalho leva a crer que o cerebelo de C. apella tem características derivadas daquele do ancestral comum aos primatas, que o leva a um parentesco maior com o homem neste aspecto, ao passo que os outros dois primatas são mais primitivos, ou seja, apresentam um maior distanciamento filogenético do homem. 
A lobulação do verme do cerebelo de C. apella, em nosso trabalho, foi descrita assim como os resultados obtidos por outros autores em animais domésticos (Zimmerl; Bossi, 1909; ZIMMERL, 1930), Cebus apella (WATANABE, 1982), animais domésticos (GETTY, 1986) e homem (DIDIO, 2002; MACHADO, 2002). Os hemisférios, porém, nos grandes ruminantes, suínos e carnívoros não apresentam lobulação (GETTY, 1986).

Em Callithrix jacchus, o verme apresenta apenas a língula e o cúlmen, sem lobulação nos hemisférios, apresentando poucas fissuras (REIS, 1975), diferindo, portanto do que observamos no C. apella.

A presença de um verme lobulado é esperada, sobretudo em mamíferos terrestres, uma vez que esta porção do cerebelo está relacionada com a manutenção do tono muscular e movimentos menos complexos.

Os hemisférios cerebelares surgiram durante a evolução dos vertebrados, auxiliando a manutenção da vida fora do ambiente aquático, garantindo uma maior coordenação dos movimentos e manutenção da postura.

Este fato explica a presença dos hemisférios nestes espécimes, porém a presença de lobulação pelas fissuras demonstra um aumento também na habilidade em executar movimentos mais delicados e complexos, como faz o homem e também o C. apella. 


\subsection{LOBO POSTERIOR}

O verme, nesta região, constitui-se pelo declive, folha do verme, túber, pirâmide e úvula, separados respectivamente pelas fissuras primária, pós-clival, horizontal, prépiramidal e secundária (pós-piramidal).

Nos hemisférios, observamos os lóbulos quadrangular posterior, lóbulos semilunares superior e inferior, tonsilas e lóbulo biventre, como estruturas correspondentes àquelas encontradas no verme. A fissura póstero-lateral separa os hemisférios do lóbulo floculonodular.

As descrições desta porção do cerebelo de $C$. apella são as mesmas citadas por Watanabe (1982); (Cebus apella), bem como Didio (2002) e Machado (2002); (humanos).

Zimmerl (1930) faz uma descrição idêntica à nossa para os lóbulos do verme, porém não faz citações a respeito das fissuras ou mesmo sobre os lóbulos quadrangulares posteriores e o lóbulo biventre.

Callithrix jacchus apresenta o verme do cerebelo pouco fissurado, com pirâmide e úvula proeminentes, porém o declive, a folha e o túber não apresentam separação nítida. Nos hemisférios estão presentes as fissuras secundária e posterolateral. A tonsila é rudimentar, os lóbulos semilunares não apresentam separação nítida e os lóbulos quadrangulares estão ausentes (REIS, 1975). Desta maneira, verifica-se uma maior complexidade no arranjo das estruturas cerebelares de C. apella que em C. jacchus.

Voogd (1975) e Getty (1986), descreveram o verme do cerebelo em primata e animais domésticos, respectivamente, apresentando as mesmas estruturas encontradas em nossas observações, porém há diferenças quanto aos hemisférios. Os dois autores citam os 
lóbulos simples, ansiforme, paramediano (GETTY, 1986) e ansoparamediano (VOOGD, 1975) como os componentes dos hemisférios do cerebelo. O primeiro refere a fissura prépiramidal e o sulco paramediano, enquanto o segundo faz referências apenas à fissura posterolateral em eqüinos.

Para carnívoros, Getty (1986) descreve apenas a presença dos lóbulos paramediano e ansiforme, nos hemisférios do cerebelo, enquanto para ruminantes e suínos não refere a existência de lóbulos e fissuras nesta região.

Mais uma vez a conformação estrutural do cerebelo de $C$. apella leva-nos a separalo dos animais domésticos, de C. jacchus, Ateles e L. albifrons, colocando-o próximo do homem, em relação ao desenvolvimento filogenético deste órgão, uma vez que apresenta todas as estruturas encontradas em seres humanos.

Contudo não é possível tecer comentários sobre diferenças comportamentais ligadas a estruturas como o lóbulo paramediano (ausente no Cebus apella e homem), pois os trabalhos não fornecem subsídios para tanto e a função de cada lóbulo do cerebelo ainda não é conhecida em seus mecanismos mais refinados. 


\subsection{LOBO FLOCULONODULAR}

Este lobo acha-se constituído por um floco bem desenvolvido em cada antímero, ligados ao nódulo pelo pedúnculo floculonodular, ocupando espaço particular dentro da cavidade craniana.

As descrições de Zimmerl et al. (1930); (animais domésticos), Hill (1962); (Ateles), Reis (1975); (C. jacchus), Getty (1986); (animais domésticos), Didio (2002) e Machado (2002) (seres humanos) coincidem com os resultados encontrados em nosso estudo do cerebelo de C. apella. Contudo as observações de Hill (1962) para Ateles identificaram o flóculo inteiramente recoberto enquanto nós o observamos bem evidente.

Não encontramos referências ao lobo floculonodular de C. apella (WATANABE, 1982) e de suínos (GETTY, 1986).

A presença de flóculos bastantes desenvolvidos em nossos animais vem reafirmar a ligação desta região com o equilíbrio, pois esta espécie é muito hábil em escaladas, saltos e caminhadas por galhos finos ou mesmo cordas em recintos fechados.

As experiências de cerebelectomia total ou parcial (WIRTH e O'LEARY, 1974), em macacos e guaxinins não são admissíveis, quer se considerando o direito dos animais de não serem submetidos a agressões em sua integridade física, quer em se levando em conta a validade do método científico. As conclusões dos trabalhos desses autores não são esclarecedoras a respeito dos mecanismos implicados na manifestação dos comportamentos pós-cirúrgicos. 
O cerebelo do macaco $C$. apella enquadra-se no padrão primata, apresentando divisão em três lobos (anterior, posterior e floculonodular), os quais são subdivididos em lóbulos por fissuras. As estruturas presentes são as mesmas do cerebelo humano, apresentando diferenças quanto à forma e tamanho.

Levando-se em consideração que as folhas aumentam a superfície do órgão e que a divisão em lóbulos permite um direcionamento mais preciso das fibras neurais para regiões específicas, podemos explicar, desta maneira, a capacidade de realização de movimentos mais elaborados por espécimes com cerebelos mais lobulados.

As informações colhidas na literatura pesquisada, bem como os dados observados em nosso trabalho, são sugestivos de que o Cebus apella possui uma intrincada organização em seu cerebelo, compatível com o vasto repertório comportamental de sua função motora. 


\section{CONCLUSÕES}

Do que acabamos de expor, julgamos poder concluir que:

1) No Cebus apella, a organização geral das estruturas componentes do cerebelo enquadra-se no padrão característico de outros primatas já estudados, principalmente o homem.

2) No cerebelo de Cebus apella, os lóbulos encontram-se bem demarcados.

3) O verme do cerebelo de Cebus apella é bastante proeminente, sobretudo na região correspondente ao lobo posterior.

4) Os flóculos do cerebelo de Cebus apella, são bastantes desenvolvidos e ocupam lugar especial na cavidade craniana.

5) Em cortes transversais do cerebelo de Cebus apella, identificam-se em cada um dos hemisférios os núcleos, denteado, globoso emboliforme e fastigial, da vista lateral para a região mediana.

6) Comparando-se os dados obtidos com a literatura, o cerebelo de Cebus apella apresenta-se, morfologicamente, em correspondência ao cerebelo dos primatas mais desenvolvidos, inclusive o homem.

7) O complexo arranjo das estruturas identificadas no cerebelo de Cebus apella é compatível com seu amplo repertório comportamental, levando-se em conta suas habilidades em escalar, saltar, capacidade de utilizar objetos como ferramentas, abrir e fechar torneiras e trincos quando em ambientes de cativeiro. 


\section{REFERÊNCIAS* ${ }^{1}$}

BOSSI, V.; CARADONA G. B.; SPAMPANI, G.; VARALDI, L.; ZIMMERL, U. Trattato di anatomia veterinaria. Milano: Casa editrice Dottor Francesco Vallardi, 1909. v.3 p. 54-62.

BROWN, A. D.; COLLILAS, O. J. Ecologia de Cebus apella. A primatologia no Brasil. In: CONGRESSO BRASILEIRO DE PRIMATOLOGIA, 1., 1983, Belo Horizonte. Anais... p. 308-309.

BRUNI, A. C.; ZIMMERL, U. Anatomia degli animali domestici / A cura. Milano: Casa Editrice Dottor Francesco Vallardi, 1947. v.2, p.485-488.

CARVALHO-BARROS, R. A. Estudo anatômico dos plexos lombar, sacral e coccígeo do macaco Cebus apella - origem, composição e nervos resultantes. 2002. 146 f. Tese (Mestrado em Ciências) - Faculdade de Medicina Veterinária e Zootecnia, Universidade de São Paulo, São Paulo, 2002.

DIDIO, L. J. A. Tratado de anatomia sistêmica aplicada. 2. ed., São Paulo: Editora Atheneu, 2002. v.2, p.806-808.

GETTY, R. Sisson/Grossman anatomia dos animais domésticos. Sistema Nervoso Central. 5. ed., Rio de Janeiro: Guanabara Koogan, 1986. v. 1, p.597-599; 1003-1005.

\footnotetext{
1 * Conforme as diretrizes para apresentaÇão de dissertaÇões e teses. 4. ed. São Paulo:
} FMVZ/USP, 2002. NBR-6023/2002. 
GETTY, R. Sisson/Grossman anatomia dos animais domésticos. Sistema Nervoso Central. 5. ed., Rio de Janeiro: Guanabara Koogan, 1986. v. 2, p.1275; 1574-1577.

HILL, W. C. O. Primates: comparative anatomy and taxonomy V Cebidae - Part B Edinburgh: University Press, 1962. p. 439-440.

LENT, R. Cem bilhões de neurônios: conceitos fundamentais de neurociência. São Paulo: Editora Atheneu, 2001. p.406-410.

MACHADO, A. B. M. Neuroanatomia funcional. 2. ed., São Paulo: Editora Atheneu, 2002. p.49-53; 218.

NAPIER, J. P.; NAPIER, P. H. Evolutionary Aspects of Primate Locomotion. American Journal of Physiology and Anthropology, 1967. v. 27, p. 333-341.

NOBACK, C. R.; STROMINGER, N. L.; DEMAREST, R. J. Neuroanatomia. estrutura e função do sistema nervoso humano, 5. ed. Local: Editorial Premier, 1999. p.81-83.

ORR, R. T Biologia de los vertebrados, 4. ed. México: Nova Editora Interamericana S.A., 1978. p.42-43.

REIS, F. P. Considerações macro e microscópicas sobre o encéfalo de Saguí (Callithrix jacchus, Linnaeus 1758)., 1975. 67 f. Tese (Mestrado em Anatomia) Escola Paulista de Medicina, São Paulo, 1975.

RODRIGUES, H. Técnicas anatômicas. Juiz de Fora: Ministério da Cultura. Univ. Federal de Juiz de Fora, 1973. p.163-164.

ROMER, A.; PARSONS, T. S. Anatomia comparada dos vertebrados. São Paulo: Editora Atheneu, 1985. p.472-474. 
SANTINI, M. E. L. Observações sobre o comportamento social e reprodutivo e reprodutivo do Cebus apella em cativeiro. A primatologia no Brasil. In: CONGRESSO BRASILEIRO DE PRIMATOLOGIA, 1., 1983, Belo Horizonte. Anais... p.65.

SWINDLER, D. R.; WOOD, C. D. An Atlas of primate gross anatomy, baboon, chimpanzee and man. Malabar, Florida: Robert E. Kriger Publishing Company, 1982. p.40.

Terminologia Anatomica Internacional. Local: Manole Ltda, 2001. p.84-85.

VOOGD, J. Bolk's subdivision of the mammalian cerebellum - growth centres and functional zones. Acta Morphol. Neerl. Scand., v.13, p.35-54, 1975.

WATANABE, I. Comparative Study of the Medulla Oblongata, Pons, Mesencephalon and Cerebellum of the Tufted Capuchin, Cebus apella LINNAEUS, 1758. Ver. Odont. São Paulo: UNESP, v. 11, n. 1/2, p.13-25, 1982.

WIRTH, F. P.; O'LEARY, J. L. Locomotor behavior of decerebellated arboreal mammals - monkey ad raccoon. Journal of Comparative Neurology, v. 157, p.53-86, 1974

ZIMMERL, U.; BRUNNI, A. C.; GARADONNA, G. B.; MANNU, A.; PREZIUSO, L. Trattato di anatomia veterinaria. Milano: Casa editrice Dottor Francesco Vallardi, 1930. v.3, p. 368-371 